Mens

revue d'histoire intellectuelle de l'Amérique française

\title{
Jacques et Raïssa Maritain au Québec et au Canada français : une bibliographie
}

\section{Yvan Lamonde et Cécile Facal}

Volume 8, numéro 1, automne 2007

URI : https://id.erudit.org/iderudit/1023156ar

DOI : https://doi.org/10.7202/1023156ar

Aller au sommaire du numéro

Éditeur(s)

Centre de recherche en civilisation canadienne-française

ISSN

1492-8647 (imprimé)

1927-9299 (numérique)

Découvrir la revue

Citer ce document

Lamonde, Y. \& Facal, C. (2007). Jacques et Raïssa Maritain au Québec et au

Canada français : une bibliographie. Mens, 8(1), 158-274.

https://doi.org/10.7202/1023156ar 


\title{
JACQUES ET RAÏSSA MARITAIN AU QUÉBEC ET AU CANADA FRANÇAIS : UNE BIBLIOGRAPHIE
}

\author{
Yvan Lamonde \\ Département de langue et littérature françaises \\ Université McGill \\ Cécile Facal \\ Département de langue et littérature françaises \\ Université McGill
}

Il n'y a pas lieu de faire ici l'histoire un tant soit peu complète de la présence et de l'influence des Maritain au Québec et au Canada français. Cependant, la bibliographie que nous proposons offre déjà les trames principales de la signification des passages de Jacques Maritain à Québec, à Montréal et à Ottawa et de la réception de ses travaux durant la première moitié du $\mathrm{XX}^{e}$ siècle. L'influence du philosophe est importante en particulier pour les générations qui reçoivent leur formation durant cette période, comme en témoigne une enquête menée en 1962 auprès d'une centaine d'intellectuels québécois : Maritain arrive alors au $5^{\mathrm{c}}$ rang parmi les auteurs les plus cités par ces intellectuels interrogés sur leurs influences ${ }^{1}$. 
Deux repères chronologiques aident à comprendre $\mathrm{Ma}$ ritain au Québec : d'une part, la période précédant et entourant la condamnation de L'Action frangaise de Paris (1926) éclaire son rôle dans le règlement de cette crise, qui a certes des échos au Québec dans les milieux nationalistes; d'autre part, la connaissance des idées du philosophe fait un bond lors de sa première visite en octobre 1934, qui sera suivie durant la guerre de deux autres séjours marquants, en 1940 et en 1943.

Le premier Maritain connu au Québec est le philosophe néo-thomiste, à la fois celui des Éléments de philosophie (1920) et des essais comme Art et scolastique (1920), Antimoderne (1922) ou Trois Réformateurs (1925). Le milieu thomiste des collèges classiques et des facultés de théologie émet d'ailleurs quelques réserves sur la pédagogie de Maritain et sur l'organisation de son cours de philosophie où, nouveauté intrigante, la psychologie précède l'ontologie et où perce une dynamique inductive peu fréquente dans la scolastique thomiste portée sur la déduction. On admire par ailleurs la curiosité du philosophe catholique qui fait honneur à l'Église : son attention à la science et à l'art annonce une ouverture bienvenue en certains milieux.

On suit attentivement à $L$ 'Action française de Montréal (1917-1928) les péripéties de la condamnation pontificale de L'Action frangaise de Paris. Et pour ceux qui, au Canada français, seraient ébranlés par cette condamnation et s'interrogeraient sur l'applicabilité des arguments romains à la revue montréalaise, des recensions de Pourquoi Rome a parlé (1927) ou Clairvoyance de Rome (1929), par exemple, suggèrent que les positions de Maritain devraient rassurer par l'énoncé des principes qu'on y trouve. L'abbé Groulx, le directeur de L'Action française de Montréal, présente ainsi Primauté du spirituel (1927) : «Ceux de chez nous néanmoins qu'auront émus ou 
troublés les récentes décisions du Saint-Siège, trouveront à rassurer leur esprit et leur foi dans les hautes spéculations du philosophe catholique ${ }^{2}$ ", évocation de la mise à l'Index du journal dirigé par Charles Maurras.

C'est au médiéviste Étienne Gilson qu'on doit le premier séjour de Maritain au Canada français, même si, dès 1922, le dominicain Marcolin-Antonio Lamarche avait publiquement lancé une invitation au philosophe catholique. C'est à Toronto, et non à Montréal ou à Québec, que le déjà réputé médiéviste français entreprend sa carrière nord-américaine en participant activement et durablement à la fondation en 1925 du Pontifical Institute of Medieval Studies avec les pères basiliens. Gilson y invite Maritain dès 1931, mais ce n'est qu'en 1933 que celui-ci peut faire la traversée pour la première fois. Ce premier séjour torontois a de rapides échos à Montréal et il n'est pas impossible que ce soit grâce à Gilson, cheville ouvrière de l'Institut scientifique franco-canadien, que Maritain séjourne à Québec, à Montréal et à Ottawa en octobre 1934, au moment où celui-ci amorce aussi sa carrière étatsunienne.

Maritain est alors lu par certains professeurs et étudiants dans certains collèges : des témoignages en rendent compte. Mais ses conférences sur "l'idéal historique d'une nouvelle chrétienté ", thème qu'il développe après l'avoir abordé à Santander en Espagne et à Poznan en Pologne en août 1934 et qui prendra forme en 1936 dans le grand ouvrage de Maritain, Humanisme intégral, constituent le moment fort de la marque intellectuelle de l'essayiste catholique. Les thèmes de la primauté du spirituel et d'un humanisme intégral traverseront les revues des jeunes comme La Releve, Vivre ou Gants du ciel. La distinction maritainienne de "l'agir en chrétien » et de "l'agir en tant que chrétien » sera au centre de réflexions sur le nationalisme; qu'on pense à l'usage qu'en fait André 
Laurendeau dans son tract des Jeune-Canada, Notre nationalisme (octobre 1935). Mais l'accueil fait à certaines idées de Maritain est loin d'être unanime; le milieu des jeunes nationalistes reçoit plutôt froidement le conseil de celui qui avait réfléchi au nationalisme en 1926: "Contentez-vous d'exister ». Les plus réceptifs trouveront un moyen de "dépasser» cette réserve en y conjuguant un autre conseil de Maritain (" être soi-même ») et en concevant une façon de se penser $e t$ comme individu ou personne et comme collectivité. L'unanimité est aussi à ce point relative que Maritain préfère ne pas venir au Québec au moment de ses prises de position sur la guerre d'Espagne; il estime que sa présence viendrait jeter de l'huile sur le feu.

Avec la déclaration de la guerre, Maritain, qui reste en Amérique, sera une des figures de la France libre - sa correspondance avec Élisabeth de Miribel en témoigne - dans un Québec qui penchera pour de Gaulle après 1942. C'est alors qu'il devient le mentor et l'un des auteurs des Éditions de l'Arbre que fondent deux membres de La Relève, Claude Hurtubise et Robert Charbonneau. Enfin, on ne peut s'empêcher de voir des difficultés faites à Maritain dans les polémiques (au sujet du professeur Hadamard, avec dom Jamet, avec Charles de Koninck) auxquelles il est confronté pendant la guerre.

Quant à Raïssa Maritain, on fait bon accueil à partir de 1940 à son œuvre poétique, en publiant des extraits de ses recueils dans divers journaux et revues. Elle contribue certainement, à travers une correspondance soutenue, à forger la vision poétique du critique Guy Sylvestre.

On le voit, la trame maritainienne est loin d'être rectiligne au Québec, même si ses conférences sont fort suivies dans la presse quotidienne comme l'indiquent les entrées dans $L e$ Devoir, Le Canada, La Presse, Le Jour, L'Action catholique, L'Évé- 
nement ou Le Droit. Nous souhaitons que la présente bibliographie suscite des travaux complémentaires et sur les Maritain et sur le sens de leurs formes variées de présence au Québec.

\section{À propos de la bibliographie}

Nos travaux sur la modernité au Québec (1930-1960) et sur La Relève requéraient une connaissance exacte de la présence des Maritain au Québec, en particulier jusqu'à la fin de la Deuxième Guerre mondiale, au moment où Maritain est nommé ambassadeur de France auprès du Vatican. Nous ne sommes pas les premiers à s'intéresser aux Maritain et il convient de reconnaitre les travaux bibliographiques et analytiques pionniers de Roland Houde et d'Yvan Cloutier, ainsi que la précieuse synthèse de Florian Michel, cités à la section 4 de la bibliographie. La bibliographie complète des æuvres de Maritain, publiée en supplément aux Cabiers Jacques Maritain ${ }^{3}$, nous a aidés à compléter le relevé des publications des Maritain au Québec en plus de fournir des renseignements sur la publication antérieure ou subséquente de ces textes.

Ces sources ont servi de matériau de base à l'établissement de la partie bibliographique de ce document. Nous y renvoyons uniquement lorsque les références et informations

- étaient inconnues de nous; les renvois sont indiqués entre crochets, selon la convention MLA ${ }^{4}$, lorsque l'étude figure à la section 4 de ce document. Dans le cas contraire, nous donnons la référence complète en note. 


\section{SOMMAIRE}

1. La correspondance québécoise et canadiennefrançaise des Maritain (1922-1945)

1.1. Correspondance manuscrite

1.2. Correspondance publiee

2. Livres et articles de Jacques et Raïssa Maritain publiés au Québec et au Canada français

2.1. Livres et articles de Jacques Maritain (1922-1950)

2.2. Luvre et articles de Raïsa Maritain (1940-1945)

3. Recensions des œuvres de Jacques et Raïssa Maritain dans les revues et journaux québécois et canadiens-français

3.1. Annonces et recensions de conférences

3.2. Recensions d'ouvrages de Jacques Maritain

3.3. Recensions d'ouvrages de Raïssa Maritain

4. Études sur Jacques et Raïssa Maritain au Québec (1920-1950) 


\section{LISTE DE SIGLES}

SCJM : Bibliographie publiée en suppléments aux $C a$ biers Jacques Maritain, Kolbsheim (France). Références complètes en note 3 .

Kolbsheim : Dépôt d'archives du Cercle d'études Jacques et Raïssa Maritain, Kolbsheim (France).

ECF : Écrits du Canada francais, Montréal.

BAC : Bibliothèque et Archives Canada, Ottawa.

CHQ : Cabiers d'bistoire du Québec au $X X^{p}$ siècle, Montréal.

CRLG : Centre de recherche Lionel-Groulx, Montréal.

DAUL: Division des archives de l'Université Laval, Québec. 


\section{La correspondance québécoise et canadienne- française des Maritain (1922-1945)}

Notre apport sera particulièrement évident à propos de la correspondance des Maritain avec des Québécois. Nous avons dû opérer un découpage en fonction de nos objets d'étude. Les correspondants retenus des Maritain sont originaires du Québec et participent d'une culture marquée d'une certaine façon par les Maritain et d'une culture qui éclaire en retour l'aventure nord-américaine des Maritain. Tout en la connaissant, nous n'avons pas retenu la correspondance des Maritain avec des compatriotes comme les pères Delos ou Couturier ou avec Jacques de Monléon, Élisabeth de Miribel ou Janvier-Louis Dalbis de l'Institut scientifique franco-canadien, par exemple. La correspondance publiée entre Maritain et Étienne Gilson et entre Maritain et Mounier est certes d'intérêt pour l'évaluation de la place de Maritain au Québec, mais elle relève d'une autre perspective. De même, l'analyse des rapports entre Maritain et des Canadiens de langue anglaise (par exemple, Norah et Roland Michener) ou de la présence de Maritain au Pontifical Institute of Medieval Studies de Toronto vaudrait bien une recherche spécifique.

Nous avons localisé à ce jour un total de 261 lettres dont 89 de Jacques Maritain et 40 de Raïssa Maritain à des correspondants québécois. Claude Hurtubise se révèle le principal correspondant de Maritain en raison de la place qu'il occupe dans la production de La Relève et, surtout, dans l'administration des Éditions de l'Arbre qu'il fonde avec Robert Charbonneau en $1940^{5}$.

Le dépôt d'archives qui s'est révélé le plus riche est celui du Cercle d'études Jacques et Raïssa Maritain à Kolbsheim, en Alsace, dirigé et animé par René Mougel, qui a accueilli Yvan Lamonde avec son sens bien connu de l'hospitalité. . Quelques lettres de Maritain ou à Maritain qui s'y trou- 
vent ont été publiées dans les Écrits du Canada français (ECF) de 1983. La richesse de Bibliothèque et Archives Canada (BAC) tient au fonds Claude Hurtubise. La correspondance qui se trouve au Jacques Maritain Center de la University of Notre Dame, à South Bend, Indiana, comprend des lettres de Québécois (Jean-Marie Gauvreau, M ${ }^{\mathrm{gr}}$ Georges Cabana), mais toutes liées à un fonds sur l'art liturgique et sacré et sans rapport avec Maritain (www.nd.edu/ maritain). Les lettres de Maritain au père Louis-Marie Régis, dominicain, sont les seules conservées aux archives dominicaines de la province SaintDominique du Canada (monastère Saint-Albert-le-Grand, Montréal) ; elles ont été publiées dans les Cahiers d'histoire $d u$ Québec au $X X^{e}$ siècle (CHQ n 6, automne 1996). Les fonds Forest, Gaudreault, Lamarche, Voyer ne contiennent pas de correspondance avec Maritain, bien que l'on connaisse une lettre publiée de Maritain au père Marcolin-Antonio Lamarche. Les archives de la University of St. Michael's College, à Toronto (voir le site www.utoronto.ca/stmikes/), ont conservé la photocopie de deux lettres aux dames Thibodeau (24 octobre 1934 et 11 novembre 1936) dont les originaux ne sont pas localisés ${ }^{7}$, ainsi que plusieurs lettres de Jacques Maritain à Guy Sylvestre ${ }^{8}$. Quelques cartes postales échangées entre Maritain et André Laurendeau, alors étudiant auprès du philosophe à l'Institut catholique de Paris, se trouvent au Centre de recherche Lionel-Groulx (CRLG). On a identifié, à la Division des archives de l'Université Laval, deux lettres échangées entre Maritain et Charles de Koninck ; à la suite des travaux de Florian Michel, et même si l'essentiel du débat entre le thomiste de Québec et celui de New York s'est tenu par publications interposées, nous savons pour les avoir mentionnées sans référence à une cote que d'autres lettres pourraient se trouver dans ce fonds, monumental par sa correspondance. 


\subsection{Correspondance manuscrite}

[1922] Maritain à Marcolin-Antonin Lamarche (Revue dominicaine, voir section 1.2)

24.10.27 Raymond-Marie Voyer, o.p., Marseille, à Maritain (Kolbsheim)

13.3.28 R.-M. Voyer, o.p., Rome, à Maritain (Kolbsheim)

24.12.31 Abbé Maurice Roy, Québec, à Maritain, Meudon (Kolbsheim)

2.10.34 Abbé M. Roy, Québec, à Maritain à bord de l'Alaunia, Pointe-au-Père (Kolbsheim)

4.10.34 Madeleine Thibaudeau à Maritain à bord de l'Alaunia (Kolbsheim)

4.10.34 $\mathrm{M}^{\mathrm{me}}$ Alfred Thibaudeau à Maritain à bord de l'Alaunia (Kolbsheim)

9.10.34 $\mathrm{M}^{\text {me }}$ Thibaudeau à Maritain a/s Dominicains de Québec (Kolbsheim)

20.10.34 $\quad \mathrm{M}^{\text {me }}$ Thibaudeau à Maritain, Meudon (Kolbsheim)

22.10.34 Madeleine Thibaudeau à Maritain, Meudon (Kolbsheim)

21.10.34 Maritain à madame Thibaudeau (archives, University of St. Michael's College, photocopie, publiée dans l'article de L. Dewan, voir section 4)

29.12.34 Éva R. Thibaudeau à Maritain, Meudon (Kolbsheim) 
16.2.35 Madeleine Thibaudeau à Maritain, Meudon (Kolbsheim)

9.8.35 Éva et Madeleine Thibaudeau à Maritain, Meudon (Kolbsheim)

[14.10.35] Maritain, Meudon, à André Laurendeau (CRLG, P2/A, 23 : carte postale)

21.10.35 Matitain, Champagnole (Jura), à A. Laurendeau (CRLG, P2/A, 11)

9.12.35 Maritain, Meudon, à Paul Beaulieu (ECF, 1983: 17-18)

27.3.36 Éva Thibaudeau à Maritain, Toronto (Kolbsheim)

6.5.36 A. Laurendeau, Paris, à Maritain (Kolbsheim)

6.36 P. Beaulieu à Maritain, Toronto (ECF, 1983 : 18-19)

26.10.36 $M^{\text {me }}$ Thibaudeau à Maritain, Meudon (Kolbsheim)

11.11.36 Maritain aux dames Thibaudeau (archives, University of St. Michael's College, photocopie, publiée dans l'article de L. Dewan, voir section 4)

18.12.36 P. Beaulieu à Maritain, Meudon (ECF, 1983 : 19-20)

4.1.37 Maritain, Meudon, à P. Beaulieu (ECF, 1983 : 21)

21.1.37 Père Bruckberger et Maritain à Charles de Koninck (DAUL, archives de Koninck) 
25.2.37 P. Beaulieu à Maritain, Meudon (ECF, 1983 : 22-23)

3.4.37 A. Laurendeau, Paris, à Maritain (Kolbsheim)

19.6.37 A. Laurendeau, Paris, à Maritain (Kolbsheim)

25.8.37 P. Beaulieu, Paris, à Maritain, Meudon (Kolbsheim)

Toussaint 37 P. Beaulieu, Paris, à Maritain, Meudon (ECF, $1983: 23$ )

3.11.37 Maritain, Meudon, à P. Beaulieu, Paris (ECF, $1983: 24)$

28.11.37 P. Beaulieu, Paris, à Maritain, Meudon (ECF, 1983 : 24-25)

28.12.37 Abbé M. Roy à Maritain, Meudon (Kolbsheim)

21.2.38 Secrétaire de Maritain à C. de Koninck (DAUL, $\mathrm{P} 112 / \mathrm{C}, 229)$

15.3.38 C. de Koninck à Maritain (DAUL, P112/C, 229)

5.9.38 Jean Le Moyne, Paris, à Maritain (Kolbsheim)

19.10.38 P. Beaulieu à Maritain, Chicago (Kolbsheim)

22.10.38 Maritain, Chicago, à P. Beaulieu (ECF, 1983 : 25-26)

31.10.38 Maritain, Chicago, à P. Beaulieu (ECF, 1983 : 26-27)

2.11.38 Maritain, Providence, à P. Beaulieu (ECF, $1983: 27$ )

4.11.38 P. Beaulieu à Maritain, South Bend (Kolbsheim)

28.11.38 Claude Hurtubise à Maritain, NY (Kolbsheim) 
30.11.38 P. Beaulieu à Maritain, NY (Kolbsheim)

$28.12 .38 \quad$ C. Hurtubise à Maritain (Kolbsheim)

25.1.39 P. Beaulieu à Maritain, Meudon (Kolbsheim)

14.2.39 Maritain, Meudon, à P. Beaulieu (ECF, 1983 : 28)

15.4.39 C. Hurtubise à Maritain (Kolbsheim)

4.1.40 C. Hurtubise et Robert Charbonneau à Maritain, Chicago (BAC)

13.2.40 P. Beaulieu à Maritain, Toronto (Kolbsheim)

5.4.40 Maritain, Chicago, à C. Hurtubise et R. Charbonneau (BAC)

2.5.40 Guy Sylvestre, Ottawa, à madame Jacques Maritain (Kolbsheim)

7.5.40 Maritain, St. John's College, Annapolis, MD à J. Le Moyne (Kolbsheim)

19.5.40 Maritain, NY, à C. Hurtubise (BAC)

19.7.40 G. Sylvestre, Ottawa, à madame Jacques Maritain (Kolbsheim)

21.10.40 Maritain, NY, à C. Hurtubise et R. Charbonneau (BAC)

26.10.40 R. Charbonneau ou C. Hurtubise à Maritain, NY (BAC)

27.10.40 Raïssa Maritain, NY, à G. Sylvestre (Kolbsheim)

29.10.40 Maritain, NY, à C. Hurtubise (BAC)

4.11.40 R. Charbonneau à Maritain, NY (BAC)

16.11.40 Maritain à C. Hurtubise (BAC) 
16.11.40 C. Hurtubise à Maritain, NY (BAC)

$19.11 .40 \quad$ C. Hurtubise à Maritain, NY (BAC)

21.11.40 Maritain, NY, à C. Hurtubise (BAC)

13.12.40 C. Hurtubise et R. Charbonneau à Maritain, NY (BAC)

13.12.40 C. Hurtubise et R. Charbonneau à Maritain, NY (BAC)

26.12.40 Maritain, NY, à C. Hurtubise (BAC)

4.1.41 C. Hurtubise et R. Charbonneau à Maritain, NY (BAC)

10.1.41 Maritain, Chicago, à C. Hurtubise (BAC)

15.1.41 Maritain, Chicago, à C. Hurtubise (BAC)

19.1.41 Maritain, Chicago, à C. Hurtubise (BAC)

20.1.41 C. Hurtubise et R. Charbonneau à Maritain, Chicago (BAC)

23.1.41 Maritain, Chicago, à C. Hurtubise (BAC)

25.1.41 C. Hurtubise à Maritain, NY (BAC)

2.2.41 Maritain, NY, à C. Hurtubise (BAC)

6.2.41 C. Hurtubise à Maritain, NY (BAC)

7.2.41 C. Hurtubise à Raïssa Maritain, NY (BAC)

25.2.41 C. Hurtubise et R. Charbonneau à Maritain, NY (BAC)

8.3.41 Raïssa Maritain, NY, à C. Hurtubise (BAC)

20.3.41 C. Hurtubise à Maritain, NY (BAC)

31.3.41 Maritain, NY, à C. Hurtubise et R.

Charbonneau (BAC) 
1.4.41 C. Hurtubise et R. Charbonneau à Maritain, NY (BAC)

5.4.41 Maritain, NY, à C. Hurtubise et R. Charbonneau (BAC)

23.4.41 C. Hurtubise et R. Charbonneau à Maritain, NY (BAC)

5.5.41 Maritain, NY, à C. Hurtubise et R. Charbonneau (BAC)

8.5.41 Madeleine Thibaudeau à Maritain, NY (Kolbsheim)

13.5.41 Raïssa Maritain, NY, à G. Sylvestre (Kolbsheim)

30.5.41 C. Hurtubise et R. Charbonneau à Maritain, NY (BAC)

7.6.41 C. Hurtubise et R. Charbonneau à Maritain, NY (BAC)

18.6.41 Maritain, NY, à C. Hurtubise et R. Charbonneau (BAC)

24.6.41 Maritain, NY, à C. Hurtubise (BAC)

26.6.41 C. Hurtubise et R. Charbonneau à Maritain, NY (BAC)

17.7.41 Maritain, NY, à G. Sylvestre (archives, University of St. Michael's College)

17.7.41 Raïssa Maritain, NY, à G. Sylvestre (Kolbsheim)

21.7.41 C. Hurtubise et R. Charbonneau à Maritain, NY (BAC) 
22.7.41 Raïssa Maritain, NY, à G. Sylvestre (Kolbsheim)

25.7.41 Maritain, NY, à C. Hurtubise (BAC, télégramme)

27.7.41 Raïssa Maritain, NY, à G. Sylvestre (Kolbsheim)

31.7.41 Raïssa Maritain, NY, à G. Sylvestre (Kolbsheim)

31.7.41 Raïssa Maritain, NY, à G. Sylvestre (Kolbsheim)

8.8.41 C. Hurtubise et R. Charbonneau à Maritain, NY (BAC)

8.8.41 Raïssa Maritain, Long Island, à G. Sylvestre (Kolbsheim)

31.8.41 Raïssa Maritain, Long Island, à G. Sylvestre (Kolbsheim)

16.9.41 Maritain, NY, à G. Sylvestre (archives, University of St. Michael's College)

23.9.41 C. Hurtubise et R. Charbonneau à Maritain, NY (BAC)

27.9.41 C. Hurtubise et R. Charbonneau à Maritain, NY (BAC)

3.10.41 Maritain, NY, à C. Hurtubise et R. Charbonneau (BAC)

4.10.41 Raïssa Maritain, NY, à G. Sylvestre (Kolbsheim)

22.10.41 C. Hurtubise et R. Charbonneau à Maritain, NY (BAC) 
26.10.41 G. Sylvestre, Ottawa, à Raïssa Maritain (Kolbsheim)

3.11.41 C. Hurtubise et R. Charbonneau à Maritain, NY (BAC)

12.11.41 Raïssa Maritain, NY, à G. Sylvestre (Kolbsheim)

12.11.41 C. Hurtubise et R. Charbonneau à Maritain, NY (BAC)

14.11.41 Maritain, NY, à C. Hurtubise (BAC)

17.11.41 C. Hurtubise et R. Charbonneau à Maritain, NY (BAC)

18.11.41 Maritain, NY, à C. Hurtubise (BAC)

21.11.41 Maritain, NY, à C. Hurtubise (BAC)

24.11.41 Raïssa Maritain, NY, à G. Sylvestre (Kolbsheim)

1.12.41 Maritain, NY, à C. Hurtubise et R. Charbonneau (BAC)

2.12.41 C. Hurtubise et R. Charbonneau à Maritain, NY (BAC)

4.12.41 Maritain, NY, à C. Hurtubise et R. Charbonneau (BAC)

14.12.41 C. Hurtubise et R. Charbonneau à Maritain, NY (BAC)

17.12.41 Raïssa Maritain, NY, à G. Sylvestre (Kolbsheim)

19.12.41 Maritain, NY, à C. Hurtubise (BAC)

[25.12.41] Maritain à C. Hurtubise (BAC) 
25.12.41 Maritain, NY, à J. Le Moyne (Kolbsheim)

[1941] Éva Thibaudeau à Raïssa Maritain (Kolbsheim)

[sans date] Raïssa et Jacques Maritain à C. Hurtubise (BAC, carte)

9.1.42 Maritain, NY, à C. Hurtubise et R. Charbonneau (BAC)

14.1.42 Raïssa Maritain, NY, à G. Sylvestre (Kolbsheim)

26.1.42 C. Hurtubise et R. Charbonneau à Maritain, NY (BAC)

30.1.42 C. Hurtubise et R. Charbonneau à Maritain, Toronto (BAC)

3.2.42 Maritain, Toronto, à C. Hurtubise (BAC)

20.2.42 C. Hurtubise et R. Charbonneau à Maritain, NY (BAC)

16.3.42 C. Hurtubise et R. Charbonneau à Maritain, NY (BAC)

18.3.42 É. Thibaudeau à Raïssa Maritain, NY (Kolbsheim)

27.3.42 C. Hurtubise et R. Charbonneau à Maritain, NY (BAC)

22.4.42 Maritain à C. de Koninck (DAUL, archives de Koninck)

24.4.42 C. Hurtubise et R. Charbonneau à Maritain, NY (BAC)

1.5.42 C. de Koninck à Maritain (DAUL, archives de Koninck) 
30.5.42 Maritain, NY, à G. Sylvestre (archives, University of St. Michael's College)

1.6.42 Maritain, NY, à C. Hurtubise et R. Charbonneau (BAC)

4.6.42 R. Charbonneau à Maritain, NY (BAC)

6.6.42 C. Hurtubise et R. Charbonneau à Maritain, NY (BAC)

9.6.42 Maritain, NY, à C. Hurtubise et R. Charbonneau (BAC)

26.6.42 C. Hurtubise et R. Charbonneau à Maritain, NY (BAC)

30.6.42 Maritain, NY, à C. Hurtubise et R. Charbonneau (BAC)

27.8.42 C. Hurtubise et R. Charbonneau à Maritain, NY (BAC)

30.8.42 Maritain, NY, à C. Hurtubise et R. Charbonneau (BAC)

30.8.42 Maritain, Croton Falls, à G. Sylvestre (archives, University of St. Michael's College)

21.9.42 Maritain, NY, à G. Sylvestre (archives, University of St. Michael's College)

[12.42] C. Hurtubise à Maritain, NY (BAC)

8.12.42 Maritain, NY à R. Charbonneau (BAC, télégramme)

11.12.42 Raïssa Maritain, NY, à G. Sylvestre (Kolbsheim)

8.1.43 C. Hurtubise à Maritain, NY (BAC) 
27.1.[43] Raïssa Maritain, NY, à G. Sylvestre (Kolbsheim)

sans date Raïssa Maritain, NY, à G. Sylvestre (Kolbsheim)

18.2.43 Raïssa Maritain, NY, à G. Sylvestre (Kolbsheim)

23.3.43 Raïssa Maritain, NY, à G. Sylvestre (Kolbsheim)

17.4.43 Raïssa Maritain, NY, à G. Sylvestre (Kolbsheim)

21.4.43 Maritain, NY, à C. Hurtubise et R. Charbonneau (BAC)

26.4.43 C. Hurtubise et R. Charbonneau à Maritain, NY (BAC)

3.5.43 Maritain, NY, à C. Hurtubise et R. Charbonneau (BAC)

4.5.43 C. Hurtubise à Maritain, NY (BAC)

6.5.43 G.-R. Benoit, Ottawa, à Maritain, NY (Kolbsheim)

8.5.43 C. Hurtubise et R. Charbonneau à Maritain, NY (BAC)

8.5.43 Maritain, NY, à G. Sylvestre (archives, University of St. Michael's College)

15.5.43 Raïssa Maritain à C. Hurtubise (BAC)

17.5.43 A. Albert à Maritain, NY (Kolbsheim)

18.5.43 Maritain, NY, à C. Hurtubise et R. Charbonneau (BAC, avec lettre au directeur du Devoir, à propos de dom Jamet) 
18.5.43 G.-R. Benoit, Ottawa, à Maritain, NY (Kolbsheim)

18.5.43 Maritain, NY, à G.-R. Benoit, Ottawa (Kolbsheim)

19.5.43 C. Hurtubise à Raïssa Maritain, NY (Kolbsheim)

19.5.43 Raïssa Maritain à C. Hurtubise (BAC)

19.5.43 Maritain, NY, à G. Sylvestre (archives, University of St. Michael's College)

20.5.43 R. Charbonneau à Maritain, NY (Kolbsheim)

20.5.43 C. Hurtubise et R. Charbonneau à Maritain, NY (BAC)

21.5.43 Maritain, NY, à G.-R. Benoit, Ottawa (Kolbsheim)

21.5.43 Marcel Raymond à Maritain, NY (Kolbsheim)

21.5.43 Raïssa Maritain à C. Hurtubise (BAC)

22.5.43 Georges Pelletier à Maritain, NY (Kolbsheim)

22.5.43 G.-R. Benoit à Maritain, NY (Kolbsheim)

22.5.43 R. Charbonneau à Maritain, NY (Kolbsheim)

22.5.43 R. Charbonneau à Maritain, NY (BAC)

23.5.43 Maritain, NY, au cardinal Villeneuve, Québec (Kolbsheim)

23.5.43 Maritain, NY, à C. Hurtubise (BAC)

24.5.43 Maritain, NY, à R. Charbonneau (BAC, carte à propos de dom Jamet)

25.5.43 Auguste J. Durelli, Montréal, à Maritain, NY (Kolbsheim) 
26.5.43 R. Charbonneau à Raïssa Maritain, NY (BAC)

27.5.43 G. Pelletier à Maritain, NY (Kolbsheim)

28.5.43 Maritain, NY, à C. Hurtubise (BAC)

29.5.43 C. Hurtubise à Maritain, NY (Kolbsheim)

29.5.43 C. Hurtubise à Maritain, NY (BAC)

31.5.43 Raïssa Maritain, NY, à C. Hurtubise (BAC)

[sans date] C. Hurtubise à Maritain (BAC, «The Cardinal takes up...", page dactylographiée)

1.6.43 Rodolphe Camirand à Maritain, NY (Kolbsheim)

5.6.43 Cardinal Villeneuve, Québec, à Maritain, NY (Kolbsheim)

9.6.43 Maritain, NY, à R. Camirand (Kolbsheim)

11.6.43 Maritain, NY, au cardinal Villeneuve (Kolbsheim)

11.6.43 Raïssa Maritain, NY, à G. Sylvestre (Kolbsheim)

11.6.43 Raïssa Maritain, NY, à C. Hurtubise (BAC)

17.6.43 C. Hurtubise à Raïssa Maritain, NY (Kolbsheim)

17.6.43 C. Hurtubise à Maritain, NY (BAC)

18.6.43 C. Hurtubise à Maritain, NY (BAC)

26.6.43 Maritain, NY, à R.Charbonneau (BAC)

26.6.43 Raïssa Maritain, NY, à G. Sylvestre (Kolbsheim)

26.6.43 Raïssa Maritain, NY, à C. Hurtubise (BAC) 
28.6.43 Maritain, NY, à G. Sylvestre (archives, University of St. Michael's College)

2.7.43 C. Hurtubise à Raïssa Maritain, NY (BAC)

8.7.43 C. Hurtubise à Maritain, NY (BAC)

12.7.43 Raïssa Maritain, NY, à C. Hurtubise (BAC)

21.7.43 C. Hurtubise à Raïssa Maritain, NY (BAC)

4.8.43 Raïssa Maritain, NY, à G. Sylvestre (Kolbsheim)

18.8.43 Raïssa Maritain, NY, à G. Sylvestre (Kolbsheim)

18.8.43 C. Hurtubise à Raïssa Maritain, NY (BAC)

31.8.43 Raïssa Maritain, NY, à C. Hurtubise (BAC)

Sans date Raïssa Maritain, NY, à G. Sylvestre (Kolbsheim)

3.9.43 C. Hurtubise à Raïssa Maritain, NY (BAC)

13.9.43 Maritain, NY, à G. Sylvestre (archives, University of St. Michael's College)

25.9.43 C. Hurtubise à Maritain, NY (BAC)

6.10.43 Raïssa Maritain, NY, à G. Sylvestre (Kolbsheim)

[9.10.43] G. Sylvestre, Ottawa, à madame Jacques Maritain (Kolbsheim)

10.10.43 Maritain, Toronto, à C. Hurtubise (BAC)

13.10.43 Maritain, Toronto, à G. Sylvestre (archives, University of St. Michael's College)

19.10.43 Maritain, Toronto, à C. Hurtubise (BAC) 
25.10 .43 C. Hurtubise à Maritain, Toronto (BAC)

25.10.43 C. Hurtubise à Raïssa Maritain, NY (BAC)

25.10.43 Maritain, Toronto, à C. Hurtubise (BAC)

27.10.43 Raïssa Maritain, NY, à C. Hurtubise (BAC)

9.11 .43 C. Hurtubise à Raïssa Maritain, NY (BAC)

18.11.43 Maritain, NY, à C. Hurtubise (BAC)

21.11.43 Raïssa Maritain, NY, à C. Hurtubise (BAC)

24.11.42 Maritain, NY, à C. Hurtubise (BAC)

29.11.43 C. Hurtubise à Raïssa Maritain (BAC)

5.12.43 Maritain, NY, à C. Hurtubise (BAC)

7.12.43 C. Hurtubise à Raïssa Maritain, NY (BAC)

13.12.43 Maritain, NY, à C. Hurtubise (BAC)

14.12.43 Maritain, NY, à C. Hurtubise (BAC)

15.12.43 C. Hurtubise à Maritain, NY (BAC)

21.12.43 Maritain, NY, à C. Hurtubise (BAC)

23.12.43 Raïssa Maritain, NY, à G. Sylvestre

- (Kolbsheim)

11.2.44 É. Thibaudeau à Raïssa Maritain, NY (Kolbsheim)

8.4.44 Maritain, NY, à G. Sylvestre (archives, University of St. Michael's College)

11.4.44 R. Charbonneau à Maritain, NY (Kolbsheim) Après 11.4.44 Maritain à R. Charbonneau (Kolbsheim) 25.4.44 Maritain, NY, au père Louis-Marie Régis ( $\mathrm{CHQ}$ $\mathrm{n}^{\circ}$ 6, automne $\left.1996: 114-115\right)$ 
3.5.44 C. Hurtubise à Maritain, NY (Kolbsheim)

4.8.44 Maritain, East Hampton, au père L.-M. Régis (CHQ no 6, automne 1996: 115)

16.8.44 C. Hurtubise à Maritain, NY (Kolbsheim)

15.10.44 Maritain, NY, au père L.-M. Régis ( $\mathrm{CHQ} \mathrm{n}^{\circ}$ 6, automne $1996: 116)$

20.10.44 Maritain, NY, à G. Sylvestre (archives, University of St. Michael's College)

29.10.44 Maritain, NY, au père L.-M. Régis (CHQ n ${ }^{\circ}$ 6, automne $1996: 116-117$ )

2.12.44 Raïssa Maritain, NY, à G. Sylvestre (Kolbsheim)

14.12.44 C. Hurtubise à Raïssa Maritain, NY (Kolbsheim)

16.12.44 C. Hurtubise à Maritain, NY (Kolbsheim)

11.1.45 Raïssa Maritain, NY, à G. Sylvestre (Kolbsheim)

5.2.45 C. Hurtubise à Maritain, NY (Kolbsheim)

5.2.45 Maritain, NY, à G. Sylvestre (archives, University of St. Michael's College)

6.2.45 P. Beaulieu, Washington, à Maritain (Kolbsheim)

17.2.45 Les Thibaudeau, télégramme à Maritain, NY (Kolbsheim)

23.2.45 Maritain, NY, à C. Hurtubise (Kolbsheim)

2.3.45 Maritain, NY, à G. Sylvestre (archives, University of St. Michael's College) 


\subsection{Correspondance publiée}

MARITAIN, Jacques. «[Lettre à M.-A. Lamarche] ", La Revue dominicaine, vol. XVIII, no 12 (décembre 1922), p. 515-516.

Remerciements pour Particle consacré à Antimoderne dans Le Devoir du 7 octobre 1922. Maritain refuse une invitation, faute de temps. La même lettre paraît dans Le Devoir du 2 décembre, p. 2 [SCJM 15, p. 27 .

"Choix de lettres de Jacques et Raïssa Maritain à Paul Beaulieu, Robert Charbonneau, Jean Le Moyne, Guy Sylvestre, 1935-1971 », Écrits du Canada français, no 49 (1983), p. 7-114.

Chacun des correspondants accompagne ses lettres d'un témoignage sur ses relations avec les Maritain (voir les notices dans la section 4).

HUOT, Giselle et Benoit LACROIX. «Lettres inédites de Chenu, Gilson et Maritain à Louis-Marie Régis, o.p. », Les Cabiers d'bistoire du Québec au $X X^{t}$ siècle, no 6 (automne 1996), p. 111-130.

Quatre lettres de Maritain, écrites de New York ou East Hampton, au père Régis, des 25 avril, 4 août, 15 et 29 octobre 1944. Originaux aux archives dominicaines, Province Saint-Dominique du Canada, monastère Saint-Albert-le-Grand, Montréal.

\section{Livres et articles de Jacques et Raïssa Maritain publiés au Québec et au Canada français}

Cette section recense les livres, articles, lettres ouvertes, préfaces, entretiens, transcriptions de conférences et recensions publiés par Jacques et Raïssa Maritain au Québec et au Canada français. Les articles parus au Canada anglais n'ont 
pas été retenus, à l'exception des quelques textes publiẹs en français. Nous n'incluons ici que les textes portant la signature des auteurs ; on trouvera plusieurs recensions de conférences, non signées mais parfois très détaillées, à la section 3 .

2.1. Livres et articles de Jacques Maritain (1922-1950, par ordre chronologique)

MARITAIN, Jacques. «De la philosophie morale adéquatement prise ", Revue de l'Université d'Ottawa, III (avril-juin 1933), p. 105*-134*. [Houde 1973-1I, 215]

-. "Le thomisme et le sens du mystère », Revue de l'Université d'Ottawa, IV (juillet-septembre 1934), p. 149*161*. [Houde 1973-II, 215]

Reproduction de l'introduction aux Sept lecons sur l'être, qui paraît en même temps chez Téqui à Paris avec quelques variantes.

—. "Le rôle temporel du chrétien », La Relève, $1^{\text {ìre }}$ série, n० 5 (octobre 1934), p. 93-97.

Ce texte sera repris et augmenté pour former une partie d'Humanisme intégral [SCJM 4-5, p. 29]. L'influence de Maritain sur le groupe de La Relève n'est plus à démontrer. En témoignent les nombreux textes publiés par lui dans la revue, mais encore plus, la fréquence avec laquelle les collaborateurs québécois de la Relève se réfèrent à ses écrits. Un nombre important de comptes rendus et d'articles sur Maritain sont recensés dans les sections suivantes, mais beaucoup plus s'y téfèrent, le citent ou s'en inspirent.

-. "À propos de la Question juive ", La Revue dominicaine, vol. XII, nº (juin 1935), p. 401-410. [Houde 1973II, 215]. 
Reproduction d'un article de La Vie spirituelle, $2^{\mathrm{e}}$ année, $\mathrm{n}^{\circ} 22$, t. II, $\mathrm{n}^{\circ} 4$ (juillet 1921). Près de quinze ans séparent la rédaction de cet article et sa reproduction dans La Revue dominicaine. Les idées qui s'y trouvent sont celles d'un Maritain encore associé à L'Action franfaise, cependant que le philosophe a significativement évolué depuis. Cet article a-t-il été reproduit avec sa permission? Une note de la première page affirme que Maritain avait promis une contribution originale qui n'a pu être livrée, mais ne dit pas s'il a suggéré le choix du texte imprimé. Maritain y concède le « rôle de subversion » des juifs, leur caractère de «ferment de révolution » (402) et énonce la " nécessité d'une lutte de salut public contre les sociétés secrètes judéo-maçonniques [...] » et de « mesures générales de préservation » (403). Il rappelle cependant l'importance de raisonner sans haine sur la question juive (404). Il note que l'Église catholique est héritière d'Israël (405), souligne la récente vague de conversion de juifs au christianisme et appelle les prières des catholiques pour que ces conversions se poursuivent (406-409). Conclusion : il faut « unir dans l'intégrité de la vie chrétienne deux vertus contraires en apparence : d'unir à la juste défense des intérêts de la cité l'amour surnaturel pour tous les hommes » (410).

"Nature de la politique ", La Relève, $2^{\text {e }}$ série, no 5 (janvier 1936), p. 131-139.

D'abord paru en 1935 dans Orientations (Paris) [SCJM 10, p. 11]. Réflexion sur « la nature de la science et de l'activité politiques », une des causes de la crise mondiale étant « la carence générale [...] d'une juste idée de la politique » (131). La distinction entre agir en chrétien et en tant que chrétien permet de comprendre ce qu'on entend par politique chrétienne (132). La rénovation chrétienne de l'ordre temporel s'oppose à une con- 
ception politiciste, qui veut faire du politique une idée technique et étrangère à la morale, dans la lignée de Machiavel (132-33). Le politique est plutôt, selon Maritain, un domaine bumain, i.e. moral (134). Pour comprendre ceci, il faut distinguer la morale individuelle (pas en cause ici) (134) et le bien commun, "bien non seulement matériel mais aussi et principalement moral» (135). En réponse à ceux qui voient dans la morale un surmoralisme, un pharisaïsme, Maritain la définit comme une activité concrète, aux règles jamais tracées d'avance (136), ce qui permet de régler le problème de la subordination de la politique à la morale (137).

-. "Témoignage ", dans RAYMOND, Marcel, Henri Ghéon, Montréal, Le Cep, 1939, p. 132-134. [SC]M 19, p. 15]

Pages tirées de La Revue fédéraliste, janvier-février 1927. «Entretien avec Jacques Maritain », Interview par Claude Hurtubise et Paul Beaulieu], La Relève, $4^{e}$ série, $n^{\circ} 8$ (mars 1939), p. 227-230.

Entretien réalisé au mois de novembre 1938 à Toronto.

Les questions portent sur le «problème des relations entre la religion et la culture et [sur le] problème du régime temporel, de la démocratie », particulièrement en ce qui concerne l'Amérique.

MARITAIN, Jacques. "L'Amérique vue : La démocratie chrétienne ", Le Jour, vol. II, no 35 (samedi 13 mai 1939), p. 4.

Reprise d'un texte publié dans Temps Présent. Maritain y présente une Amérique consciente du « péril couru par la civilisation » et de la nécessité de défendre la démocratie et [d']élaborer une nouvelle démocratie " selon les valeurs chrétiennes. Citant les évêques américains, il présente aux Français l'exemple d'un épiscopat démo- 
crate ; citant le président Roosevelt, il donne l'exemple d'un politique qui «reconnaît la religion comme la source de la démocratie et de la bonne foi internationale ». Il s'agit bien entendu d'une démocratie renouvelée, rénovation qui doit se faire par la redécouverte de son « principe vital » : « la justice, la justice et l'amour, dont la source est divine ».

—. "L'Évangile et l'Empire païen ", La Relève, 4" série, no 9 (juillet 1939), p. 257-264.

Fragment d'une conférence donnée à Paris en 1939, qui deviendra une partie du Crépuscule de la civilisation (note $1 \mathrm{du}$ texte). Sur la conception du politique dans l'Empire païen, i.e. séparé de la pensée chrétienne, et incarné ici dans le national-socialisme allemand. Celuici repose sur « le principe du contre l'autre », de la haine de l'ennemi. Maritain y oppose la leçon de l'Évangile.

LIMAGNE, Pierre. Témoignage sur la situation actuelle en France, par un dirigeant français d'Action Catholique, préface de Jacques Maritain, Montréal, Éditions de l'Arbre, 1941. [Houde 1973-II, 216]

Dans sa préface, Maritain raconte comment il a reçu ce manuscrit et explique pourquoi, malgré certains désaccords avec son auteur - qui garde trop de ménagements envers le régime de Vichy -, il a voulu le rendre accessible aux lecteurs catholiques canadiens et américains. Il s'agit d'empêcher les catholiques de « se laisser mystifier " par la propagande allemande, celle notamment qui prétend mener en Russie une "croisade» contre le communisme.

MARITAIN, Jacques. Le Crépuscule de la civilisation, Montréal, Éditions de l'Arbre, 1941.

Une édition légèrement différente a paru en 1939 aux Éditions des Nouvelles Lettres à Paris [Houde 1973- 
II, 215]. C'est le premier livre publié par les Éditions de l'Arbre. Il contient un avant-propos absent de l'édition originale. Rééditions à L'Arbre en 1941 dans la collection «Problèmes actuels ", puis en 1944. [SCJM 19, p. 27-28]

—. "L'humanisme de Saint Thomas d'Aquin », Mediaeval Studies [Toronto], vol. III (1941), p. 174-184. [SCJM 19, p. 31]

\section{-. "Le Peuple de France», La Revue domini-}

caine, vol. XLVII, nº 1 (janvier 1941), p. 6-18. [Houde 1973II, 216]

Ces pages, qui formeront le chapitre III de À travers le désastre (New York, Maison française, 1941) [Houde 1973-II, 216], sont publiées ici «en primeur ». Maritain y soutient que le malheur de la France est un cas particulier d'un malheur universel, causé par une fausse philosophie de la vie qui a altéré pendant des années le principe vital des démocraties. Il dément des thèses radiodiffusées lors de l'armistice, selon lesquelles la décadence des Français aurait causé la défaite (6-7). Il réprouve cette « fuite dans la morale »; certes, la France a péché, mais comment cela pourrait-il expliquer la défaite, alors que «les péchés des vainqueurs crient contre le ciel » (10) ? Le peuple est responsable d'avoir eu de mauvais chefs, d'avoir accepté d'être " parasité " par la classe politique, et de ce que la vie politique n'émanait pas de la vie profonde du peuple (8-9).

MARITAIN, Jacques et Raïssa. « Notre Maître perdu et retrouvé ", La Revue dominicaine, vol. XLVII, $\mathrm{n}^{\circ} 2$ (février 1941), p. 61-68. [Houde 1973-II, 216]

Hommage à $\mathrm{H}$. Bergson à l'occasion de sa mort. Souvenirs, dettes et prises de distance. L'évolution de la pensée de Bergson au cours des ans rapproche le maître et ses élèves de jadis. 
MARITAIN, Jacques. «Descartes et la religion», La Revue dominicaine, vol. XLVII, nº 5 (mai 1941), p. 232-241.

Reprise avec retouches légères d'un texte paru dans la revue Cbristus (Paris-Lyon), n ${ }^{\circ} 38$ (septembre-octobre 1937). Sera repris dans Pour la justice (1945) [SCJM 10, p. 25].

—. "Peuple de France », Le Droit, samedi 31 mai 1941. [SCJM 19, p. 34]

Extraits d'A travers le désastre. Guy Sylvestre est alors responsable de la page littéraire du Droit d'Ottawa.

-.. "Profession de foi », "Poésie et métaphysique », " La cité chrétienne », "Armes spirituelles », Le Droit, samedi 30 août 1941, p. 18. [SCJM 19, p. 35]

Extraits de la Réponse à Jean Cocteau (1926), des Degrés du savoir (1932), d'Humanisme intégral (1936) et De la vie d'oraison (Jacques et Raïssa, 1922), accompagnant un article de Guy Sylvestre intitulé « Jacques Maritain apôtre de l'esprit » et des poèmes de Raïssa Maritain.

-.. "Poésie et mystique ", Le Droit, samedi 13 décembre 1941, p. 18. [SCJM 19, p. 35]

Extraits des Degrés du savoir (1932) et de Frontières de la poésie (1935).

MARITAIN et al. Devant la crise mondiale. Manifeste de catholiques européens séjournant en Amérique, New York, Maison française, 1942.

Jacques et Raïssa Maritain signent ce manifeste rédigé par Auguste Viatte, professeur à l'Université Laval'.

MARITAIN, Jacques. "Spontanéité et indépendance », Mediaeval Studies, vol. IV (1942), p. 23-32.

Sera repris dans De Bergson à Thomas d'Aquin (1944) [SCJM 19, p. 41]. 
—. "Sur la doctrine de l'Aséité divine », Mediaeval Studies, vol. V (1942), p. 39-50.

Extraits d'un cours sur la liberté donné en 1937-1938

à l'Institut catholique de Paris [SCJM 19, p. 53].

bre 1942, p. 2. [SCJM 19, p. 44]

Réponse à une lettre aux Français d'A. de Saint-Exupéry publiée par Le Canada le 30 novembre sous le titre «Voulez-vous, Français, vous réconcilier ? ». L'échange a d'abord paru dans le New York Times pour la lettre de Saint-Exupéry et dans Pour la victoire, pour la réponse de Maritain. Après l'occupation de la zone libre par l'Allemagne et la disparition du régime de Vichy, Saint-Exupéry appelle à la réconciliation des Français afin de s'unir dans la lutte armée. Maritain reconnaît la droiture de ses intentions et la générosité de son appel, mais refuse d'oublier la collaboration de ceux qui ont abdiqué en juin 1940, en particulier celle des chefs. Vichy n'est pas la France, insiste-t-il afin de dissiper une confusion entretenue par la lettre de Saint-Exupéry. Une rectification de Saint-Exupéry, brève et courtoise, figure à la suite.

Il faut parfois juger, Ottawa, Service de l'Information

de la France Combattante, «Documents de la France Combattante », no 4, 1943, 12 p. [SCJM 19, p. 45]

- - "Les Laïques catholiques et le monde d'aprèsguerre ", Le Catbolique devant la guerre, Montréal, RadioCanada, 1943, p. 125-142. [Houde 1973-II, 216]

Conférence lue sur les ondes de Radio-Canada le 2 mai 1943, puis rediffusée le 9 mai, dans le cadre de la série «Le catholique devant la guerre », inaugurée par le cardinal Villeneuve le 7 février 1943. Le texte est aussi publié dans un grand nombre de journaux qué- 
bécois : Le Canada, 5-6 mai 1943, p. 4 [Cloutier 2002, 230] ; L'Action catholique, 4-5 mai 1943, p. 4 ; Le Nouvelliste, 6 mai 1943, p. 3, 9 et 12. Des extraits paraissent le 3 mai dans Le Droit, p. 7 ; La Patrie, p. 4 ; La Presse, p. 7 [SCJM 19, p. 51]. Ce texte est à l'origine des controverses avec Dom Jamet. Il donna aussi lieu à plusieurs articles élogieux.

" Jacques Maritain nous écrit », Le Canada, lundi 3 mai 1943, p. 4.

Controverse à propos de Jacques Hadamard. Maritain répond ici à une lettre aux lecteurs anonyme, intitulée «Qui est donc ce M. Hadamard » et publiée dans Le Devoir du 6 avril 1943, qui accusait J. Hadamard, professeur à l'École Libre des Hautes Études de New York, d'anticléricalisme et de franc-maçonnerie. C'est à titre de directeur de l'École Libre que Maritain répond aux accusations portées contre son collègue mathématicien, en énumérant ses titres honorifiques et en évoquant le respect dont il jouit dans les communautés scientifiques du monde entier. La lettre paraît le même jour dans Le Dèvoir, accompagnée d'une réplique. Répertorié sous le titre «Défense de Jacques Hadamard " dans SCJM 19, p. 55.

—. «Qui est M. Hadamard? suivi de Lettre de M. Maritain ", Le Devoir, lundi 3 mai 1943, p. 10. [Cloutier 2002, 230]

La lettre de Maritain est la même que dans la notice précédente. Dans sa réplique, l'« Universitaire de langue française " porte à nouveau ses accusations et critique les mauvaises fréquentations de Maritain. La direction du journal, dans une $N$. de la $R$, se plaint de ce que la lettre de Maritain a été envoyée au Canada: on avait pourtant fait jadis à Maritain une si bonne publicité [sic !]. 
—. "Lettres au Devoir», Le Devoir, samedi 22 mai 1943, p. 2. [SCJM 19, p. 55]

Présentation par la rédaction du différend opposant Maritain à l'" Universitaire de langue française », dont le ton ne laisse aucun doute sur la position du journal (peu sympathique à Maritain). Suivent deux lettres adressées au rédacteur en chef par Maritain et l'« Universitaire ». Maritain affirme la non-pertinence des questions posées par l'« Universitaire » sur les convictions religieuses de J. Hadamard, alors que celui-ci, dans sa lettre, s'entête à déplorer que Maritain évite d'y répondre. Cet échange semble clore le débat.

—. "Le cas de M. Jacques Maritain ", Le Devoir, mercredi 26 mai 1943, p. 2. [SCJM 19, p. 55]

Réponse de Maritain à l'article du 15 mai de Dom Jamet (voir notice section 4), suivie de sa réplique. Les deux documents occupent presque toute une page, ce qui signale l'importance du débat pour la direction du journal. Maritain y rectifie les nombreuses « erreurs de fait » de la lettre de Jamet. Il explique la nature de son association avec L'Action française et ses positions dans la crise de 1926; il justifie et maintient la position de neutralité (contre Franco et contre le communisme) prise durant la guerre civile espagnole ; il critique durement les positions de Jamet vis-à-vis de Vichy et y oppose celles d'autres religieux hostiles au régime; il répond enfin avec verve aux attaques personnelles portées contre lui. Maritain termine sa lettre, en réponse aux propos de Jamet qui lui reproche de vouloir être un chef, en réitérant sa volonté « de penser et d'agir en cbrétien ». Répertorié sous le titre "Réponse à Dom Jamet » dans SCIM 19, p. 55. A.J. Durelli, J. Le Moyne et M. Raymond prendront la défense de Maritain dans ce débat (voir notices dans la section 4). 
"La vraie signification du racisme », La Revue dominicaine, vol. XIIX, no 5 (mai 1943), p. 257-265.

Parties du discours de clôture prononcé le 25 janvier 1943 lors d'une séance de l'Institut de droit comparé de l'École Libre des Hautes Études de New York, paru d'abord dans le recueil des communications de cette séance, Le Droit raciste à l'assaut de la civilisation (New York, Maison française, 1943) [SCJM 19, p. 51-52].

- « "Lettre de nuit. La Vie donnée. Par Raïssa Maritain ", La Nouvelle Relève, vol. II, no 8 (juillet-août 1943), p. 499-501. [Houde 1973-II, 216]

Recension du recueil de poèmes de Raïssa Maritain reprenant le texte d'une notice " prière d'insérer » de la première édition du recueil dans la collection «Les Îles » chez Desclée de Brouwer, Paris, 1939. L'introduction est différente dans l'édition montréalaise, qui contient elle aussi le "prière d'insérer" [SCJM 19, p. 14 et 58].

—. " La Conquête de la liberté », Gants $d u$ ciel $\iota^{10}, \mathrm{n}^{\circ} 1$ (septembre 1943), p. 85-109. [Houde 1973-II, 216]

Reprise du chapitre "The Conquest of Freedom », paru dans R.N. Anshen (dir.), Freedom, Its Meaning, New York, Harcourt Brace, 1940 (note 1 du texte). Sera repris dans Principes d'une politique bumaniste, New York, Maison française, 1944 [SCJM 19, p. 61]. Sur la « liberté d'épanouissement de la personne humaine », distincte de la liberté de choix, qui en est le présupposé.

-. "Sur le Jugement artistique ", La Revue dominicaine, vol. XLIX, no 9 (septembre 1943), p. 65-68. [Houde 1973II, 216]

Il s'agit de la première publication de ce texte [SCJM 19, p. 51]. Maritain donne ici sa définition de l'art : « un effort créateur dont la source est spirituelle, et qui nous livre tout à la fois le soi le plus intime de l'artiste et les 
secrètes correspondances qu'il a perçues dans les choses, par une vision ou une intuition qui lui est propre et qui est [...] exprimable seulement dans une cuvre » (6566). Le jugement artistique consiste à juger si l'artiste a ou non quelque chose à dire (66). « Le premier devoir de l'artiste et du poète est d'être inébranlablement fidèles à leur vérité " (66).

- "L'Immortalité de l'âme ", La Nouvelle Relève, vol. III, $\mathrm{n}^{\circ} 1$ (décembre 1943), p. 1-18.

Texte d'une conférence prononcée par Maritain à Montréal le 11 novembre 1943 sous les auspices de l'ACFAS. Traduction par l'auteur de « The Immortality of Man ", paru dans The Review of Politics, vol. 3, $\mathrm{n}^{\circ} 4$ (octobre 1941). Sera repris ensuite dans De Bergson à Thomas d'Aquin, New York, Maison française, 1944 [SCJM 19, p. 29].

-. "Le Machiavélisme et l'éthique politique », La Revue dominicaine, vol. L, n०1 (janvier 1944), p. 6-24.

Extraits de Principes d'une politique bumaniste, en primeur. -. "Machiavel ou l'illusion du succès immédiat ", $L a$ Nouvelle Relève, vol. III, $\mathrm{n}^{\circ} 2$ (janvier-février 1944), p. 65-85.

Article déjà publié en anglais dans la Review of Politics de janvier 1942. À paraître à New York sous le titre Principes d'une politique bumaniste (note 1 de l'article).

- "La conquête de la liberté », Les Carnets viatoriens" ${ }^{11}, 9^{e}$ année, no 2 (avril 1944), p. 153-158.

« Extraits, sous forme analytique, de l'étude parue sous le même titre dans Gants du ciel.» [SCJM 19, p. 69]

-. Humanisme intégral. Problèmes temporels et spirituels d'une nouvelle chrétienté, Montréal, Éditions de l'Arbre, 1945.

Réimpression des Éditions Aubier (Paris, 1936). 
—. "L'impossible antisémitisme », dans Paul CLAUDEL et al., Les Juifs, Montréal, Éditions de l'Arbre, 1945, p. 4471.

Réimpression du volume paru chez Plon (Paris, 1939, coll. «Présences »).

MARITAIN, Jacques, Ambassadeur de France auprès du Vatican. "Le Peuple de France », France-Canada, Ottawa, vol. III, $\mathrm{n}^{\circ} 3$ (mars 1945), p. 10. [Houde 1973-II, 216]

EMMANUEL, Pierre. Combat avec tes défenseurs, préface de Jacques Maritain, Montréal, Éditions Lucien Parizeau, $1946^{12}$.

Édition originale : Paris, Pierre Seghers, 1945. Robert Élie mentionne l'édition québécoise dans un article sur Pierre Emmanuel paru dans La Nouvelle Relève en $1945^{13}$. Ceci porte à croire que la date de publication au Québec est 1945 plutôt que 1946.

MARITAIN, Jacques. Éléments de philosopbie I. Introduction générale à la philosophie, $20^{e}$ édition, Paris/Montréal, Téqui/ Granger, $1946^{14}$.

Édition originale : Paris, Téqui, 1920.

- Éléments de philosophie II. L'ordre des concepts: 1. petite logique (logique formelle), $13^{e}$ édition, Paris/Montréal, Téqui/ Granger, $1946^{15}$.

Édition originale : Paris, Téqui, 1920.

_. "Beati qui persecutionem patiuntur propter justitiam [Bienheureux ceux qui souffrent persécution pour la justice] ", La Nouvelle Relève, vol. V, $\mathrm{n}^{\circ} 6$ (janvier 1947), p. 481-493. 
Reproduit sous forme de fascicule publicitaire pour La Nouvelle Relève et les Éditions de l'Arbre (s.d.) [Houde 1973-II, 217].

—. «Léon Bloy ou le pèlerin de l'absolu », Conférence à l'Alliance française de Montréal (vendredi 19 octobre 1934), répertoriée par E. Tétreau dans Esquisses biographiques des Conférenciers de l'Alliance Française, $1^{e}$ série, Comité de Montréal, École industrielle des Sourds-Muets, 1949, p. $74-$ 76. [Houde 1973-II, 215]

\subsection{Livre et articles de Raïssa Maritain (1940-1945)}

MARITAIN, Raïssa. «Arbres », La Rotonde, vendredi 2 février 1940, p. 1.

Poème tiré de Lettre de nuit-I a vie donnée (Paris, Desclée de Brouwer, 1939) ${ }^{16}$.

-. "Quelques souvenirs sur Ève Lavallière », La Rotonde, mardi 20 février 1940, p. 4.

Ce texte sur une célèbre actrice convertie et entrée dans les ordres sera remanié et repris dans Les Aventures de la grâce (New York, Maison française, 1944, tome II des Grandes Amitiés). Repris aussi, sous le même titre, dans Ie Droit, 15 janvier 1944, p. $2^{17}$. Tout porte à croire que cette collaboration avec le journal étudiant puis le quotidien d'Ottawa est due à Guy Sylvestre.

-_. «Poëmes : Nocturne, Louange de l'épouse, De

Profundis ", La Relève, 5 série, $\mathrm{n}^{\circ} 1$ (avril 1940), p. 20-22.

Poèmes tirés de Lettre de nuit - La vie donnée.

—. «La Croix du Sud», La Rotonde, jeudi 25 avril 1940, p. 4.

Poème tiré de Lettre de nuit-La vie donnée ${ }^{18}$. 
SYLVESTRE, Guy. Situation de la poésie canadienne, lettrepréface de Raïssa Maritain, Ottawa, Le Droit, 1941. [Houde 1973-II, 216]

Le titre de ce petit recueil d'essais sur la poésie canadienne (un essai général et deux études de Regards et jeux dans l'espace de Saint-Denys Garneau et d'Axe et parallaxes de François Hertel) renvoie à Situation de la poésie de Jacques et Raïssa Maritain (Paris, Desclée de Brouwer, 1938). Raïssa Maritain remercie Sylvestre d'engager ce « dialogue » avec « ceux pour qui la poésie n'est ni une "distraction", ni un art "d'agrément", ni une facile effusion sentimentale, mais un mode de connaissance $[. .$.$] ». La poétesse expose dans ces quelques$ pages sa conception de la poésie. Elle y discute aussi certains des jugements exposés par Sylvestre dans l'ouvrage. Claude Hurtubise mentionne cette préface de Raïssa dans une recension dans la Nomvelle Relève, vol. I, n 1 , p. $30-31$ et 50 .

MARITAIN, Raïssa. "Henri Bergson, souvenirs », La Relève, $5^{\mathrm{e}}$ série, $\mathrm{n}^{\circ} 6$ (mars 1941), p. 161-167.

Article d'abord paru en traduction anglaise dans Commonweal (janvier 1941). Sera repris dans Le Droit, samedi 3 mai $1941^{19}$.

-. "Nocturne », Le Droit, samedi 10 mai 1941, p. 5.

«Reproduction fautive d'un poème de Lettre de nuit $t^{20}$. "

-. "Les Grandes Amitiés. Léon Bloy », Le Droit, samedi 16 août 1941, p. 18.

Extrait des Grandes Amitiés, alors à paraître (New York, Maison française, 1941) ${ }^{21}$.

—. "Arbres », " Lettre de nuit », "La croix du sud », Le Droit, samedi 30 août 1941, p. 18. 
Poèmes tirés de Lettre de nuit-La vie donnée. Cette page contient également un extrait de De la vie d'oraison (Jacques et Raïssa, Paris, Art catholique, 1925). Toute la page est consacrée à Jacques et Raïssa Maritain ${ }^{22}$.

-_. « À l'Aube de nouvelles amitiés », La Nouvelle Relève, vol. I, n² (octobre 1941), p. 65-70.

Quelques pages sur G. Rouault qui seront reprises dans Les Grandes Amitiés [Houde 1973-II, 216].

- Lettre de nuit. La vie donnée, Montréal, Éditions de l'Arbre, 1943.

Réimpression d'un recueil paru en 1939 chez Desclée de Brouwer (Paris, collection «Les Îles »).

-. "Louange de l'épouse » et «La vérité, la foi », La Rotonde, vendredi 5 février 1943, p. 3 et 8.

Numéro spécial intitulé "Notre formation». Le premier texte est un poème tiré de Lettre de nuit - La vie donnée ; le second est une étude datée de $1943^{23}$.

“Souvenirs », Gants du ciel, n² (décembre 1943), p. 61-79. [Houde 1973-II, 216]

Souvenirs de la fin du séjour de Jacques et Raïssa Maritain en Allemagne (1906-1907), du Père Clérissac et de sa direction spirituelle, de la lecture de saint Thomas qui, selon R. Maritain, réconcilie la foi avec la raison. Louanges à saint Thomas. Retravaillé pour Les Aventures de la grâce.

- "Pierre et Christine ", La Revue dominicaine, vol. L, $\mathrm{n}^{\circ} 2$ (octobre 1944), p. 129-138. [Houde 1973-II, 216]

Sur le «frère » et la " sœur » de Jacques et Raïssa Maritain, Pierre et Christine van der Meer de Walcheren, convertis et, comme eux, filleuls de Léon Bloy. L'article relate le parcours du couple d'amis vers la conver- 
sion en insistant sur le rôle de Bloy, raconte leur vie après la conversion et l'entrée au couvent de leurs deux enfants. À la mort de leur fils, ils décident de se séparer pour entrer en religion chacun de leur côté. Ils en sortent après deux ans, sur les conseils du supérieur. Pierre van der Meer de Walcheren dirige les éditions Desclée de Brouwer, à Paris. Extrait des Aventures de la grâce.

-. "Lettre de Raïsa Maritain », La Nouvelle Relève, vol. III, n 9 (décembre 1944), p. 522.

Lettre publiée à l'occasion de la mort d'Hector de SaintDenys Garneau.

- " "Deus Excelsus Terribilis », La Nonvelle Relève, vol. III, $\mathrm{n}^{\circ} 10$ (janvier 1945), p. 581-586.

Poème.

—. «André Gide », La Revue dominicaine, vol. LI (février 1945), p. $120-123$.

En note : «Mme M. en réponse à ce qui la concerne dans "André Gide ou l'art de la fugue", livraison de janvier, p. 38, nous demande de reproduire cet extrait des Grandes Amitiés, t. II, p. $219 \mathrm{~s}^{24}$. »

\section{Recensions des œuvres de Jacques et Raïssa Maritain dans les revues et journaux québécois et canadiens-français}

\subsection{Annonces et recensions de conférences (par ordre chronologique)}

Cette section comprend les comptes rendus et les annonces des conférences données par Jacques Maritain au Québec. Nous y incluons les annonces, car elles révèlent l'ampleur de la diffusion publique dont ont joui ces visites. Les quotidiens Le Devoir, La Presse et Le Canada de Montréal ainsi que L'Action catbolique et L'Événement de Québec ont été dé- 
pouillés pour les dates correspondant aux visites de Maritain au Québec, soit les mois d'octobre 1934, de février 1940 et de novembre 1943. Le Jour (fondé à Montréal en 1937) a également été dépouillé pour les périodes correspondant aux visites de 1940 et 1943. Le Devoir a en outre été consulté pour les périodes du 3 avril au 24 mai 1933, et de janvier 1934 [séjours à Toronto], ainsi que du $1^{\text {er }}$ juillet au 7 août 1937 [Guerre civile espagnole].

\section{3}

"Jacques Maritain viendra l'an prochain", Le Devoir, lundi 3 avril 1933, p. 1. [Houde 1973-II, 215]

Petite colonne : Édouard Montpetit annonce pour l'année suivante des cours de Maritain sous les auspices de l'Institut scientifique franco-canadien. Il devait venir cette année, mais le voyage est reporté à l'année suivante. Brève présentation du philosophe.

«Jacques Maritain À Toronto », Le Devoir, lundi 3 avril 1933, p. 7.

Quinze lignes sur le départ de Maritain de Toronto. Le sous-titre précise : « Le philosophe français s'en retoume en France par Boston et New York après avoir donné des cours à l'Institut des études médiévales du Collège Saint-Michel ».

GIRARD, René, S.J. «Lettre sur Maritain. À propos des cours professés à Toronto par l'éminent philosophe français ", Le Devoir, mercredi 24 mai 1933, p. 1-2. [Houde 1973-II, 215]

«Chronique » du séjour de J. Maritain à Toronto, en réponse à une demande d'Omer Héroux à l'auteur. Sur les locaux où ont lieu les cours ; sur Maritain luimême ; sur le sujet des cours. 
«M. J. Maritain à l'Université », L'Action catholique, lundi 8 octobre 1943, p. 3.

10 lignes d'annonce pour les deux conférences données les 8 et 9 octobre à l'Université Laval, portant sur «La tragédie de l'humanisme » et « Science et sagesse ».

« J. Maritain à l'Université », L'Événement, lundi 8 octobre 1934, p. 3.

Annonce de la série de causeries à l'Université Laval. On mentionne que ce n'est pas la première annonce.

«Bienvenue à Jacques Maritain », L'Événement, lundi 8 octobre 1934, p. 4.

En page éditoriale, mot de bienvenue, annonce des cinq conférences et présentation de Maritain comme "l'âme du renouveau catholique de son pays ». On insiste sur sa qualité de converti et de convertisseur, d'« apôtre ", en rappelant notamment son influence sur Enest Psichari.

«M. Jacques Maritain à l'Université Laval. Première conférence de l'éminent philosophe français. - "Science et sagesse". - Comment le monde antique et le monde moderne ont compris la sagesse. - $\mathrm{M}^{\mathrm{gt}}$ Pâquet présente le conférencier ", L'Action catholique, mardi 9 octobre 1934, p. 3 et 9.

Ce court article reprend des éléments de la présentation faite par $\mathrm{M}^{\mathrm{gr}}$ Pâquet, lequel insiste surtout sur le choix louable de Maritain de se consacrer au travail de l'esprit, par opposition à l'action dans le monde. Suit un bref résumé de la conférence intitulée « Science et sagesse 》. 
"Jacques Maritain chez nous", L'Action catbolique, mardi 9 octobre 1934, p. 4.

Ce court article imprimé dans la page éditoriale reprend quelques mots de la présentation de Maritain par $M^{\text {gr }}$ Pâquet, avant d'inciter « tout homme entretenant quelque prétention à la culture » à aller écouter ses conférences.

"Jacques Maritain à l'Université Laval », L'Événement, mardi 9 octobre 1934, p. 12 et 11.

Résumé de la conférence « Science et sagesse ». «Emparons-nous des sommets dans le domaine des sciences ", L'Action catbolique, mercredi 10 octobre 1934, p. 3 et 9.

Compte rendu de la cérémonie de clôture du congrès de l'ACFAS contenant une recension du discours de Maritain, dans lequel le philosophe précise qu'il appelle non pas à un retour au Moyen Âge, mais à la réconciliation de la sagesse et de la science moderne.

«Les conférences de M. Jacques Maritain », L'Action catholique, mercredi 10 octobre 1934, p. 9.

Recension de la conférence du 9 octobre sur l'« idéal historique d'une nouvelle chrétienté ». On insiste sur le fait que la nouvelle chrétienté n'est pas un retour au Moyen Âge : «Dans la nouvelle civilisation l'œuvre commune ne devra apparaitre comme une æuvre divine à réaliser sur terre, $[. .$.$] mais comme une civilisa-$ tion qui admettra l'idée évangélique de la personne humaine et de sa dignité. » Sur la même page, on trouve une annonce pour deux autres conférences à l'Université Laval (sur « La tragédie de l'humanisme » et sur le nouvel humanisme, respectivement les 10 et 12 octobre) et pour une causerie sur l'enseignement de la philosophie destinée aux professeurs (11 octobre). 
«L'ACFAS », Le Devoir, mercredi 10 octobre 1934, p. 1.

Dix lignes. Clòture du congrès de l'ACFAS (tenu à Québec), où Maritain a prononcé un discours.

"Trois discours au banquet de l'Acfas », L'Événement, mercredi 10 octobre 1934, p. 3 et 13.

Compte rendu du discours de Maritain à la clôture du congrès de l'ACFAS.

" $2^{\mathrm{e}}$ conférence de Jacques Maritain », L'Événement, mercredi 10 octobre 1934, p. 3 et 13.

Résumé de la conférence sur le monde médiéval.

"Les conférences de M. Jacques Maritain. Mtr $^{\text {tr }}$ Camille Roy, P.A, présente le conférencier. - M. Maritain traite de la "tragédie de l'humanisme". - L'humanisme anthropocentrique est inhumain. - Il faut revenir à l'humanisme chrétien ", L'Action catbolique, jeudi 11 octobre 1934, p. 11.

Le journaliste mentionne le grand succès des conférences de Maritain à Québec avant de rendre compte de la conférence de la veille.

« $4^{\mathrm{e}}$ conférence de Jacques Maritain », L'Événement, jeudi 11 octobre 1934, p. 14.

Résumé de la conférence sur la tragédie de l'humanisme. Le titre devrait se lire : « $3^{e}$ conférence $[. .$.$] ».$

«Conférence de M. J. Maritain », L'Action catholique, vendredi 12 octobre 1934, p. 3.

Très bref compte rendu de la causerie avec les professeurs de philosophie. Maritain met l'acçent sur l'élève, qui « doit jouer un rôle plus important que le professeur » dans l'enseignement de la philosophie.

«Les conférences de M. Maritain. Les sujets, les dates et l'endroit ", Le Devoir, vendredi 12 octobre 1934, p. 2. 
«Les conférences de M. Jacques Maritain », L'Action catholique, samedi 13 octobre 1934, p. 3.

Compte rendu de la conférence du 12 octobre sur le nouvel humanisme chrétien. On reconnait Humanisme intégral (à paraitre, 1936).

«M. Maritain au séminaire », L'Événement, samedi 13 octobre 1934 , p. 3 .

Très bref compte rendu de la causerie avec les professeurs de philosophie.

« $4^{\mathrm{e}}$ conférence de Jacques Maritain ", L'Événement, samedi 13 octobre 1934, p. 16.

Compte rendu de la conférence «Communisme et athéisme $\%$.

H. G. « Bienvenue à M. Jacques Maritain », Le Canada, lundi 15 octobre 1934, p. 2.

Annonce de la venue de Maritain, présenté comme quelqu’un qui « vit pour la pensée et la vérité », venu " familiariser les intelligences avec les hautes idées de la philosophie officielle du catholicisme », et comme un « initiateur des intelligences moyennes aux vérités difficiles ». Son rôle est présenté comme "plus modeste [que celui d'autres grands philosophes catholiques,] quoique très méritoire. Il est un de ceux qui ont rajeuni la philosophie thomiste, ou mieux qui lui ont redonné la vie $[\ldots] \%$.

O[mer]. H[éroux]. « M. Jacques Maritain », Le Devoir, lundi 15 octobre 1934, p. 1.

Petite colonne. Annonce de la venue de Maritain, courte présentation élogieuse, mot de bienvenue. 
«M. Jacques Maritain. Sa grande simplicité de manières Son air de jeunesse - Méthode de travail — Sa meilleure collaboratrice - L'Institut catholique - Au Canada ", Le Devoir, lundi 15 octobre 1934, p. 3.

Les journalistes ont interviewé le philosophe. L'article consiste en un portrait, accompagné d'un aperçu de ses méthodes de travail et du travail de sa femme. On y trouve aussi des propos sur l'Institut catholique de Paris, sur l'importance de la participation des laïques au développement de la philosophie française et, enfin, l'annonce de ses conférences à Montréal.

«Maritain dans la Métropole », L'Action catholique, mardi 16 octobre 1934, p. 1.

Quelques lignes du correspondant de Montréal annonçant l'arrivée de Maritain et recueillant ses commentaires.

HARVEY, Jean-Charles. «La vie des idées. La métaphysique chrétienne de Jacques Maritain », Le Canada, mardi 16 octobre 1934, p. 2.

J.-Ch. Harvey évoque une rencontre informelle de Maritain avec un groupe d'intellectuels qui se réunissent régulièrement au restaurant Kerhulu de Québec, puis présente les grandes lignes de deux des quatre conférences prononcées à l'Université Laval de Québec, auxquelles il a assisté. On reconnait dans la distinction entre deux humanismes (anthropocentriste et théocentrique), dans les propos sur l'athéisme du communisme tusse et sur le "petit-bourgeois ", les thèses d'Humanisme intégral.

«La tragédie de l'humanisme », Le Canada, mardi 16 octobre 1934, p. $3^{25}$. 
«M. Maritain au Plateau », Le Devoir, mardi 16 octobre 1934, p. 1.

Dix lignes. Annonce de sa conférence du soir.

«Les problèmes spirituels et temporels d'une nouvelle chrétienté. La conférence donnée hier soir par $\mathrm{M}$. Jacques Maritain sur la tragédie de l'humanisme ", Le Devoir, mardi 16 octobre 1934, p. 2-3. [Houde 1973-II, 215 (avec titre abrégé)]

Compte rendu détaillé de la première conférence d'un cycle de quatre sur les « problèmes spirituels et temporels d'une nouvelle chrétienté », prononcée à la salle Saint-Sulpice. Le texte n'est pas signé, mais plusieurs parties s'apparentent à une transcription en style direct. La salle était comble, temarque le journaliste : plusieurs auditeurs ont dû rester debout. On reconnait, dans le compte rendu de la conférence, l'argumentation d' $\mathrm{Hu}$ manisme integral.

"M. Jacques Maritain au "Cercle Universitaire" : "Bergson et saint Thomas" », Le Devoir, mardi 16 octobre 1934, p. 8.

Vingt lignes. Annonce d'un déjeuner-conférence le samedi 20 octobre à $13 \mathrm{~h}$.

REYNALD. «La tragédie de la pensée humaniste », La Presse, mardi 16 octobre 1934, p. 24. [Cloutier 1995, 70]

Compte rendu. L'auteur note la foule nombreuse et l'importante délégation d'ecclésiastiques présents.

F. L. «L'exposé d'un nouvel humanisme. M. Jacques Maritain fait une vaste récapitulation historique du spirituel », $L e$ Canada, mercredi 17 octobre 1934, p. 3.

Résumé de la deuxième conférence à l'École du Plateau : « Un nouvel humanisme ». Propos qu'on retrouvera dans Humanisme intégral. 
«L'hommage à Maritain. L'allocution du R. P. M.-A. Lamarche, O.P.», Le Devoir, mercredi 17 octobre 1934, p. 4. [Houde 1973-II, 215 (avec titre abrégé)]

Texte de l'allocution présentée le lundi soir à la salle Saint-Sulpice. Citations de Réflexions sur l'intelligence sur l'universalité de la philosophie thomiste. Éloge de ce que certains appellent l'intransigeance de Maritain, que Lamarche préfère nommer sa " complète honnêteté ". Sur la fausseté de l'idée selon laquelle Maritain et les autres restaurateurs du thomisme rejettent en bloc toute nouveauté, inscrivant ainsi Maritain entre "nouveauté" et tradition (" sa parole autorisée viendra confirmer ce qui a été enseigné dans notre faculté et dans les scolasticats de la ville et de la banlieue [...] ». Lamarche souligne la présence du clergé, des universitaires et des professionnels ainsi que de femmes, laissant entendre que le consensus s'établit alors autour de la personne et de l'œuvre de Maritain.

« M. Maritain à L'Alliance Française », Le Devoir, mercredi 17 octobre 1934, p. 7.

Cinq lignes. Annonce de la conférence du vendredi soir. «Les problèmes spirituels et temporels d'une nouvelle chrétienté. La deuxième conférence de M. Jacques Maritain sur : un nouvel humanisme ", Le Devoir, mercredi 17 octobre 1934 , p. 8 .

Texte de la $2^{e}$ conférence du cycle de quatre, au Plateau. Le texte n'est pas signé, mais plusieurs parties s'apparentent à une transcription en style direct. Là encore, ce sont les thèses qui seront développées dans Humanisme intégral: exposition des deux positions pures qu'on trouve au terme de l'évolution historique des temps modernes : la position chrétienne pure et la position athéiste pure. Maritain expose les « raisons profondes " de l'athéisme russe comme principe du communisme. 
Il explique que le communisme aurait des origines chrétiennes, et esquisse le processus de substitution de ces valeurs chrétiennes opéré par le marxisme. L'homme collectif est alors substitué à l'homme-personne. La nouvelle chrétienté, conclut-il, devra transfigurer non seulement l'homme, mais aussi les structures sociales.

REYNALD. «L'humanisme d'une nouvelle chrétienté », La Presse, mercredi 17 octobre 1934, p. 24. [Cloutier 1995, 70] "Le rôle de la science dans la synthèse du savoir. Conférence de $M$. Jacques Maritain sous les auspices de l"ACFAS" ", Le Devoir, jeudi 18 octobre 1934, p. 8. [Houde 1973-II, 215 (avec titre abrégé)]

"Voici un résumé du magistral exposé de M. Maritain. ». Hors du cycle de quatre conférences, celle-ci traite du même sujet sous un autre angle, plus technique. La sagesse est supérieure à la science ; Maritain va "caractériser les grandes positions prises dans l'Antiquité, dans le monde chrétien et dans le monde moderne à l'égard des ces deux termes [...] : sagesse et science. " À la fin de l'article, annonce de la conférence du soir à l'école du Plateau.

"Jacques Maritain à l'Institut des études médiévales », Le Droit, jeudi 18 octobre 1934, p. 9.

Annonce des trois conférences organisées à Ottawa par l'Institut des études médiévales, les 21, 22 et 23 octobre. La même annonce sera reprise le samedi 20 octobre 1934, p. 14.

REYNALD. « Pour redonner son rang à la sagesse ", La Presse, jeudi 18 octobre 1934, p. 18. [Cloutier 1995, 70]

F. L. «Le chrétien et le monde. M. Jacques Maritain pronostique le rôle et la gloire du laïcat chrétien », Le Canada, vendredi 19 octobre 1934, p. 3. 
Suite du cycle de conférences à l'École du Plateau sur les problèmes spirituels et temporels d'une nouvelle chrétienté. Universalité de la religion chrétienne.

«Cours et conférences de M. Maritain », Le Devoir, vendredi 19 octobre 1934, p. 1.

Dix lignes d'annonces. Le soir même au Ritz : conférence sous les auspices de l'Alliance française. Le lendemain à $11 \mathrm{~h}$ : fin du cycle de quatre conférences à la salle Saint-Sulpice; le lendemain à $13 \mathrm{~h}$ : causerie sur Bergson au Cercle universitaire.

"M. Maritain au "Cercle Universitaire" ", Le Devoir, vendredi 19 octobre 1934, p. 1.

Annonce de 5 lignes.

«Les Problèmes spirituels et temporels d'une nouvelle chrétienté. Le chrétien et le monde - Le spirituel et le temporel - Le Royaume de Dieu - La mission temporelle du chrétien à l'égard de l'instauration d'un nouvel ordre chrétien du monde. La Conférence de M. Jacques Maritain, hier soir », Le Devoir, vendredi 19 octobre 1934, p. 6. [Houde 1973-II, 215 (avec sous-titre abrégé)]

L'article, non signé, passe du discours indirect au discours direct. Long compte rendu de la $3^{\mathrm{e}}$ conférence du cycle de quatre. Maritain présente la position chrétienne pure.

REYNALD. «Le chrétien dans le monde nouveau ", La Presse, vendredi 19 octobre 1934, p. 19. [Cloutier 1995, 70] « M. Maritain à l'Alliance française. "Je pouvais devènir un saint, je suis un homme lettré", a dit Léon Bloy ", Le Canada, samedi 20 octobre 1934, p. 4.

Recension de la conférence de la veille au Ritz, à l'invitation de l'Alliance française. 
"Léon Bloy, le "mendiant ingrat", a donné une voix à la multitude des pauvres et des oubliés. Il se considérait chargé de dénoncer l'iniquité du monde où il vivait — Sa foi immuable - Vocation de pauvreté et de misère Comment s'explique la violence de son langage ", Le Devoir, samedi 20 octobre 1934, p. 3.

Conférence à l'Alliance française. «En voici un bien bref et trop pâle résumé » écrit l'auteur de cet article.

«Léon Bloy, le pèlerin de l'absolu », La Presse, samedi 20 octobre 1934, p. 24. [Cloutier 1995, 70]

PERRIER, abbé Armand, collaboration spéciale. «Les Conférences de M. Jacques Maritain ", La Presse, samedi 20 octobre 1934, p. 24.

Il s'agit non pas d'un résumé, mais d'une réflexion sur cette visite de Maritain et sa signification, suivie d'un relevé des points tirés des conférences qui paraissent susceptibles d'une application immédiate.

F. L. «M. Maritain, hôte du Cercle universitaire. Il indique les faiblesses du bergsonisme et le devoir du thomisme ", Le Canada, lundi 22 octobre 1934, p. 3.

Résumé de la causerie sur Bergson du samedi midi.

«Au Cercle Universitaire. M. Maritain, Bergson et saint Thomas. Devant un bel auditoire, M. Jacques Maritain prononce la dernière de la belle série de ses conférences à Montréal », Le Devoir, lundi 22 octobre 1934, p. 2.

Recension de la causerie du samedi midi précédent au Cercle universitaire. Le texte n'est pas signé, mais plusieurs parties s'apparentent à une transcription en style direct. Le conférencier rappelle des souvenirs de Bergson et montre quelle est la faiblesse de son système : il laisse de côté la raison, l'intelligence. Saint Thomas y 
remédie. Or, le danger du thomisme et de la scolastique, c'est d'être justement scolaire, poursuit Maritain. Elles doivent se renouveler au contact de la réalité, afin d'être une philosophie qui observe et qui vive. [Cet article et celui de la notice suivante, en p. 8 du Devoir du même jour, sont répertoriés en un seul sous « Bergson et saint Thomas » dans Houde 1973-II, 215.]

POULIN, Père Gonzalve. "Comme un souffle d'espoir ", Le Devoir, lundi 22 octobre 1934, p. 3.

Lettre des lecteurs. L'auteur voit dans le fait qu'un philosophe aussi abstrait que Maritain remplisse les salles l'annonce d'« un goût inédit chez nous pour la chose religieuse » et espère que cela saura « développer chez nous une nouvelle forme de littérature et tarir à jamais l'orientation actuelle, si lourdement documentaire. "

"Les conférences de M. Maritain. Le conférencier explique comment une société chrétienne peut renaître, mais différente sous plusieurs aspects, de la société chrétienne du moyen âge ", Le Devoir, lundi 22 octobre 1934, p. 8.

"Compte rendu schématique » de la conférence du samedi matin (dernière de la série de quatre sur les problèmes spirituels et temporels d'une nouvelle chrétienté). Le compte rendu détaillé est reporté au lendemain. Non signé.

«La sagesse et la science. Ouverture des cours de M. Jacques Maritain chez les Dominicains. - Présidence d'honneur de Monsieur le ministre de France ", Le Droit, lundi 22 octobre 1934, p. 10.

Compte rendu de la conférence donnée la veille, fort courue par « l'élite intellectuelle religieuse et laïque de la capitale $\gg$. Le journaliste fait une liste des notables présents. Maritain est présenté par le R.P. Peghaire comme «l'ennemi irréconciliable et les plus influent des doctri- 
nes destructives de l'ordre chrétien, de l'athéisme des adeptes de Moscou et de l'irréligion doucereuse de trop de nos contemporains. "Résumé détaillé de la conférence ( 3 colonnes).

REYNALD. «La chrétienté de l'époque à venir », La Presse, lundi 22 octobre 1934, p. 15. [Cloutier 1995, 70]

F. L. «La chrétienté doit être tolérante. M. Jacques Maritain dit ce que doit être l'idéal d'une nouvelle chrétienté », Le Canada, mardi 23 octobre 1934, p. 3.

Recension de la dernière conférence du cycle de quatre sur une nouvelle chrétienté, prononcée samedi avantmidi.

"L'Idéal historique d'une nouvelle chrétienté. Dernière conférence de $M$. Jacques Maritain sur les problèmes spirituels et temporels d'une nouvelle chrétienté ", Le Devoir, mardi 23 octobre 1934, p. 8 et mercredi 24 octobre 1934 , p. 10 et 7. [Houde 1973-II, 215 (avec sous-titre abrégé)]

Transcription de la conférence du 20 octobre.

"Philosophie et sciences. Deuxième cours de M. Jacques Maritain. - Présidence d'honneur de S.E. M ${ }^{g r}$ Guillaume Forbes, archevêque d'Ottawa ", Le Droit, mardi 23 octobre 1934 , p. 3.

Liste des notables présents. Compte rendu détaillé de la conférence portant sur le débat opposant la philosophie et les sciences, et en particulier sur le problème de la philosophie de la nature, ou de la physique.

«Monsieur Jacques Maritain. Une conférence de M. Maritain sur la philosophie chrétienne au Scolasticat SaintJoseph ", Le Droit, mardi 23 octobre 1934, p. 12.

Compte rendu d'une rencontre avec la communauté du Scolasticat suivie d'une conférence. 
"L'idéal historique d'une nouvelle chrétienté. M. Jacques Maritain parle hier soir à l'Université d'Ottawa. - La nouvelle chrétienté sera "communautaire" ", Le Droit, mercredi 24 octobre 1934, p. 9.

Liste des notables présents et compte rendu détaillé de la conférence.

"Philosophie et théologie. Troisième cours de M. J. Maritain. - Présidence d'honneur de S.E. M. Raymond Brugère, ministre de France au Canada », Le Droit, mercredi 24 octobre 1934, p. 11.

Liste des notables présents et compte rendu détaillé de la dernière conférence donnée à l'Institut d'études médiévales, portant sur le « débat de la philosophie et de la théologie, ou plutôt du problème si actuel de la philosophie chrétienne $»$. L'article se termine sur une transcription des remerciements adressés à Maritain par le R.P. B. Mailloux, o.p., président de l'Institut.

LA RELÈVE. «Les problèmes spirituels et temporels... d'une nouvelle chrétienté », La Relève, $1^{\text {re }}$ série, $\mathrm{n}^{\circ} 5$ (octobre 1934), p. 118-122 et 101.

Compte rendu des conférences données par Maritain à Montréal la semaine précédente.

“Conférences », La Rotonde, 1"er novembre 1934, p. 155.

Mention de la conférence prononcée à l'Université d'Ottawa le 23 octobre.

VOYER, R.-M. "Remerciements à M. Jacques Maritain », La Revue dominicaine, vol. XI, $\mathrm{n}^{\circ} 12$ (décembre 1934), p. 380-384. [Houde 1973-II, 215]

Discours prononcé le soir de la conférence au Cercle universitaire. L'auteur a étudié à Paris avec Maritain. Il rappelle la place d'honneur dont jouit le thomisme au 
Canada, de tout temps. Mais il craint que ce ne soit ici une philosophie de musée : « souvent regardée et même de temps à autre rafraîchie, mais fixée tout de même, sans vie » (381), il craint que nous soyons « bergsoniens sans le savoir » (i.e. sujets à l'indolence intellectuelle) (382). « Notre renaissance thomiste, à nous, ne consisterait-elle pas à rendre vraiment productif et agissant ce qui a été placidement gardé jusqu'ici ? [...] La pensée est, doit être une vie, voilà ce que nous laissera votre souvenir. » (383)

-. "Jacques Maritain », Revue trimestrielle canadienne, vol. I, ñ 1 (décembre 1934), p. 7.

\section{5}

«Allocution de Monsieur Maritain », Annales de l'ACFAS, vol. I (1935), p. 116-117.

Résumé du discours prononcé lors du banquet de clôture du congrès de l'ACFAS, le 9 octobre 1934, à Québec.

1936

«M. Jacques Maritain », Le Devoir, vendredi 10 janvier 1936 , p. 1.

Annonce de l'arrivée de Maritain en Amérique du Nord. L'Institut scientifique franco-canadien compte l'inviter à Montréal. Cette visite n'aura pas lieu.

1939

"Maritain ne viendra pas ! , Le Jour, 28 janvier 1939, p. 1.

Voici le texte intégral de cette courte annonce, en une du journal: «Nous apprenons de source bien informée que l'éminent écrivain et conférencier catholique 
français Jacques Maritain, qui devait revenir cette année donner à Québec et à Montréal une série de conférences, ne viendra pas, contrairement à ce qu'on avait précédemment annoncé en ce sens. Qu'est-ce qui a pu motiver ainsi ce changement de décision? Craindraiton en quelques milieux québécois l'influence que pourrait avoir sur notre peuple le catholicisme éclairé de cet esprit d'élite? »)

«Les cours de Jacques Maritain », Le Devoir, vendredi 2 février 1940.

Quinze lignes. Annonce de la venue prochaine du philosophe.

«Les conférences de M. Jacques Maritain. Lundi, mardi et mercredi prochains », Le Devoir, jeudi 15 février 1940, p. 12.

Quinze lignes. Annonce des conférences de la semaine suivante.

"À l'Institut. M. Jacques Maritain de retour parmi nous », Le Devoir, lundi 19 février 1940, p. 3.

Une colonne sur le séjour de Maritain et les conférences prévues. Maritain refuse de prendre position publiquement sur la guerre.

"Les conférences de M. Jacques Maritain. La Philosophie bergsonienne de la morale et de la religion ", Le Devoir, lundi 19 février 1940 , p. 6.

Dix lignes. Annonce de la première conférence.

«Les conférences de M. Maritain en notre ville », La Presse, lundi 19 février 1940, p. 11 et 24.

Le sous-titre se lit: "Le célèbre philosophe donnera trois leçons en l'École Technique ». Rédigé à la suite 
d'une rencontre avec les journalistes, pendant laquelle Maritain a refusé de se prononcer sur les événements internationaux. Annonce des conférences à venir et propos sur Bergson, sur la personne humaine et sur la société et l'égalité, sujets de ses conférences.

" Jacques Maritain parle du grand philosophe Bergson », Le Canada, mardi 20 février 1940, p. 6.

Résumé de la conférence de la veille, dans laquelle Maritain traite de Bergson et considère sa philosophie en regard de celle de saint Thomas.

«Les conférences. M. Jacques Maritain et la philosophie de Bergson », Le Devoir, mardi 20 février 1940, p. 9.

Une colonne. Résumé de la conférence de la veille et annonce de celle du lendemain.

«Les conférences. Le deuxième cours de M. Jacques Maritain. Relations entre la personne et la société », Le Devoir, mercredi 21 février 1940, p. 7.

Une colonne. Résumé de la conférence de la veille.

«M. Jacques Maritain à l'Alliance française », Le Devoir, mercredi 21 février 1940, p. 8.

Dix lignes. Annonce de la conférence du vendredi suivant.

"L'éminente valeur de la personne humaine », La Presse, mercredi 21 février 1940 , p. 9.

Le sous-titre se lit : « Maritain rappelle qu'en doctrine thomiste, celle-ci fait partie de la société, mais de par sa fin surnaturelle lui est supérieure. » Compte rendu de la conférence de la veille. Le journaliste inscrit les propos de Maritain dans la mouvance personnaliste d'Esprit, pour cette conférence portant sur la distinc- 
tion entre les notions d'individu et de personne et sur l'inscription de la personne dans la société.

"La conception chrétienne de la nature humaine », Le Canada, jeudi 22 février 1940, p. 5 .

Résumé de la conférence de la veille, intitulée : « L'égalité chrétienne ». Maritain a distingué trois conceptions de l'homme : empiriste, idéaliste et réaliste. La dernière, qui « admet l'égalité de nature entre les hommes», est privilégiée par le philosophe. Les inégalités de fait entre les hommes ne doivent pas, selon lui, être supprimées, mais «compensées par la justice sociale ». On mentionne les remerciements adressés à Maritain par Édouard Montpetit.

"Une théorie nuancée de l'égalité humaine », La Presse, jeudi 22 février 1940, p. 14.

Compte rendu de la conférence de la veille.

"Une leçon de Jacques Maritain », Le Canada, 5 mai 1943, p. 4.

Éloges de la causerie diffusée les 2 et 9 mai 1943 à Radio-Canada.

«M. Jacques Maritain à la Société d'Étude », La Presse, vendredi 5 novembre 1943, p. 4.

Quinze lignes d'annonce de la conférence du mardi suivant sur Bergson.

"Le rôle de la France. Opinions de M. J. Maritain concernant le destin de son pays ", La Presse, lundi 8 novembre 1943 , p. 3 et 23.

Écrit à partir d'une interview, où Maritain affirme croire qu' il y a beaucoup de chances pour que la France 
joue un rôle important après la guerre », notamment « un rôle de trait d'union entre l'Europe et le monde slave d'une part et les grandes puissances occidentales, les États-Unis, le Canada, l'Angleterre, d'autre part. " Maritain croit en la réalisation d'une $I V^{\mathrm{e}}$ République. Programme des cours et conférences.

LAPORTE, Pierre. «M. J. Maritain attire plus de trois cents élèves à son cours », Le Canada, mardi 9 novembre 1943, p. 11.

Reportage sur le premier d'une série de cinq cours sur la liberté à l'Université de Montréal. Annonce des prochains cours et autres conférences inscrits au programme de cette visite.

"Les entrevues. M. Jacques Maritain », Le Devoir, mardi 9 novembre 1943 , p. 3.

Début du séjour. Annonce du programme de conférences et entrevue. Portrait physique : " Maritain a peu changé depuis une dizaine d'années que nous avons eu le privilège de ses visites ». Sur son travail aux ÉtatsUnis, sur la jeunesse américaine, dont il découvre la soif d'apprendre et les hautes préoccupations. Maritain donne des nouvelles de France et des écrivains français qui sont pour la plupart "restés fidèles à la liberté » au lieu de "passer à la collaboration».

"Conférence de M. Maritain ", L'Action catholique, mercredi 10 novembre 1943 , p. 8.

Très bref compte rendu de la conférence de la veille sur "La philosophie bergsonienne " et annonce des activités de la semaine.

"Conférence de Jacques Maritain, au Windsor ", Le Canada, mercredi 10 novembre 1943, p. 11.

Annonce de la conférence «Autorité et démocratie ». 
"M. Maritain à la société d'études et de conférences », Le Canada, mercredi 10 novembre 1943, p. 12.

Sous-titre : « Le savant philosophe parle de la philosophie bergsonienne de la morale et de la religion $»$. La conférence porte sur les Deux sources de la morale et de la religion de Bergson. Compte rendu d'une colonne.

«La philosophie bergsonienne. M. Jacques Maritain à la Société d'Études et de Conférences ", Le Devoir, mercredi 10 novembre 1943 , p. 5.

Sur la conférence de la veille portant sur Bergson. On note qu'à cette époque, Maritain « réhabilite » Bergson (à la lumière des Deux sources de la morale et de la religion), après l'avoir durement critiqué en 1913. Annonce de la conférence du lendemain.

"La doctrine bergsonienne, M. Jacques Maritain parle du grand philosophe à la Société d'étude », La Presse, mercredi 10 novembre 1943 , p. 4.

Résumé de la conférence de la veille.

LAPORTE, Pierre. «Chronique universitaire : Inauguration officielle du cours universitaire de l'année [...] Deuxième cours de M. Jacques Maritain sur la liberté [...] ", Le Canada, jeudi 11 novembre 1943, p. 3.

Dans cette chronique sur les actualités universitaires, très bref résumé du cours de la veille à l'Université de Montréal, sur «le jugement et sur la nature du libre arbitre ».

«Démocratie et autorité », Le Devoir, jeudi 11 novembre 1943 , p. 3.

Bref résumé de la conférence de la veille. 
«Jacques Maritain conférencier à l'Institut démocratique canadien. ", L'Événement, jeudi 11 novembre 1943, p. 3 et 11.

Le sous-titre apporte des précisions sur l'événement : «I e grand philosophe français parle de la démocratie en fonction de l'autorité. - Première conférence publique de l'Institut démocratique. - Présidence de M. T.D. Bouchard. - L'hon. Gouin présente le conférencier. »

"Autorité et liberté à concilier. M. Maritain propose d'y parvenir au moyen de la "démocratie organique" ", La Presse, jeudi 11 novembre 1943, p. 15.

Compte rendu de la conférence de la veille, sous les auspices de l'Institut démocratique canadien, et présidée par T.-D. Bouchard, ministre de la Voirie. Le sénateur Léon-Mercier Gouin a présenté le philosophe.

LAPORTE, Pierre. «Chronique universitaire : L'immortalité, une certitude naturelle et philosophique [...] Conférence de M. Jacques Maritain à l'Université de Montréal hier soir [...] ", Le Canada, vendredi 12 novembre 1943, p. 12 et 2.

Une centaine de spectateurs étaient présents pour cette conférence sur l'immortalité de l'âme, rapporte le journaliste, avant de donner un résumé substantiel des propos du philosophe.

«M. Maritain et l'immortalité de l'âme », Le Devoir, vendredi 12 novembre 1943, p. 9.

Trois paragraphes. Bref résumé de la conférence donnée à l'auditorium de l'université sous les auspices de l'ACFAS.

«La personne humaine est immortelle. Conférence de M. Jacques Maritain, hier soir, à l'Université », La Presse, vendredi 12 novembre 1943, p. 19. 
Résumé de la conférence de la veille, donnée à l'invitation de l'ACFAS et de la Société de philosophie de Montréal.

"Les trois formes de démocratie », L'Action catholique, samedi 13 novembre 1943, p. 19.

Bref résumé de la conférence de la veille sur les rapports entre la "démocratie et l'autorité », dans l'optique d'une nécessaire réorientation des régimes démocratiques après la guerre.

"Jacques Maritain à Montréal », Le Jour, samedi 13 novembre 1943 , p. 4.

Dans l'impossibilité de donner un compte rendu de la conférence donnée à l'Institut démocratique canadien, le journal offre quelques notes biographiques sur le conférencier.

"Une causerie de monsieur Maritain », L'Action catbolique, lundi 15 novembre 1943, p. 9.

Résumé de la conférence de la veille au Cercle universitaire de Montréal, intitulée « La fin du machiavélisme », où Maritain condamne le machiavélisme des régimes hitlérien et mussolinien.

LAPORTE, Pierre. «La justice politique est un facteur essentiel de bonheur. Brillante causerie de M. Jacques Maritain sur "la fin du machiavélisme" au Cercle universitaire. Dilemme des démocraties [...] ", Le Canada, lundi 15 novembre 1943 , p. 3.

Résumé de cette dernière conférence à Montréal, à laquelle ont assisté trois cents personnes. Compte rendu détaillé.

«Le machiavélisme ne réussit qu'à engendrer le malheur des hommes ", Le Devoir, lundi 15 novembre 1943, p. 5. 
Résumé étendu ( 2 colonnes) de la causerie de la veille au Cercle universitaire.

"Réfutation du machiavélisme. "Philosophie de la politique qu'il faut détruire", dit Jacques Maritain », La Presse, lundi 15 novembre 1943, p. 12.

Dîner-conférence organisé par le Cercle universitaire. Le journaliste note le souci de vulgarisation dont a fait preuve Maritain, à la grande appréciation du public. Résumé de la conférence avec photo. Maritain fut présenté par le $\mathrm{D}^{\mathrm{O}}$ Oscar Mercier, président du Cercle, et remercié par le R.P. Ceslas Forest, O.P., doyen de la Faculté de philosophie de l'Université de Montréal.

3.2. Recensions d'ouvrages de Jacques Maritain (ordre chronologique) GAGNÉ, Florido. «Jacques Maritain, Éléments de Pbilosophie. Fascicule I, Introduction à la Philosophie [...] », Enseignement secondaire au Canada, III (1919-1920), p. 272-273. [Cloutier 1995]

Ouvrage paru à Paris chez Téqui, 1920.

« J. Maritain. - Éléments de Pbilosophie, Introduction génétale à la philosophie [...] ", La Revue dominicaine, vol. XXVI, $\mathrm{n}^{\circ} 10$ (octobre 1920), p. 320. [Cloutier 1995]

P. S. "Jacques Maritain, Théonas, [...], Nouvelle Librairie Nationale, 1922 ", Le Canada français, vol. IX, no 1 (septembre 1922), p. 78. [Cloutier 1995]

Compte rendu élogieux de Théonas ou les entretiens d'un sage et de deux pbilosophes sur diverses matières inégalement actuelles, paru en 1921 ('auteur se trompe sur la date de parution). L'auteur en conseille la lecture et loue le respect du thomisme de Maritain. 
A[rthur]. R[obert]. «Jacques Maritain, Antimoderne [...]. Édition de la Librairie des Jeunes [...] Paris ", Le Canada franfais, vol. IX, $\mathrm{n}^{\circ} 2$ (octobre 1922), p. 156. [Cloutier 2002]

Ouvrage paru à l'été 1922. L'auteur souligne l'inspiration thomiste de ce qui est décrit comme un combat " pour le triomphe complet de la philosophie scolastique $»(157)$.

LAMARCHE, M.-A. "À propos d"“Antimoderne" ", La Revue dominicaine, vol. XXVIII, $\mathrm{n}^{\circ} 11$ (novembre 1922), p. 454-457. [Cloutier 1995]

L'auteur fait bon accueil à Antimoderne, admettant volontiers que «la philosophie moderne a fait son temps » (454). Il souligne l'ouverture de Maritain aux avancées scientifiques et artistiques, faisant de lui l'exemple du thomiste qui se tient " toujours "en avant du mouvement de recherche [...], recueillant avec sollicitude, purifiant, rectifiant et dirigeant tout effort vers le vrai. [...]" " (454). Le compte rendu s'achève avec un souhait : voir « l'apparition sur nos estrades [à la faculté de philosophie de l'Université Laval] de M. Jacques Maritain " (457). Le texte est reproduit du Devoir du 7 octobre 1922 (indiqué en fin d'article). En réponse à ce compte tendu, une lettre de remerciement de Maritain paraît dans La Revue dominicaine et dans Le Devoir, en décembre 1922 (notice section 1.2).

ROBERT, Arthur. "Chronique philosophique », Le Canada français, vol. X, no 1 (février 1923), p. 56-69. [Cloutier 1995]

Recension d'Éléments de philosopbie I (Paris, Téqui, 1920).

Le recenseur reconnaît la valeur de l'ouvrage, mais n'est pas d'accord avec la méthode. Maritain choisit de présenter les sujets "pratiques" (psychologie et cosmologie) avant ceux « qui n'ont plus rien de matériel », tels l'ontologie ou la métaphysique, privilégiant une progression du concret vers l'abstrait (58-59). A. Robert 
juge quant à lui «plus profitable de se servir de la méthode [...] déductive » (59). Les pages 61 et suivantes portent sur un article de Maritain sur « La métaphysique des physiciens " - dont Einstein - paru dans la Revne universelle (X, 10, août 1922). Maritain y critique la raison scientifique qui n'accepte de s'exercer que sur ce qu'elle peut mesurer, accordant toutefois son admiration au génie d'Einstein.

A[rthur] R[obert]. "Jacques Maritain, Eléments de philosopbie, II, l'ordre des concepts. 1 Petite logique (logique formelle) [...] P. Téqui, Paris, 1923 », Le Canada français, vol. XII, $\mathrm{n}^{\circ} 4$ (décembre 1924). [Cloutier 1995]

Recension nuancée de ce deuxième volume du manuel de Maritain. L'auteur n'est pas toujours d'accord avec Maritain, mais reconnaît la valeur de l'ouvrage. La didactique, la rigueur et le ton sont loués ; certaines opinions sur des «questions somme toute secondaires» sont discutées.

BASTIEN, Hermas. «Trois réformateurs, par Jacques Maritain », L'Action française, vol. XIV (juillet 1925), p. 322-323.

Recension de Trois Réformateurs. Luther, Descartes, Rousseau, Paris, Plon, 1925 (premier volume paru dans la collection "Le Roseau d'Or», dirigée par Maritain). L'auteur qualifie déjà Maritain de « célèbre philosophe thomiste » et fait allusion à Antimoderne, déjà connu. Il loue l'ouvrage et sa méthode.

L[ionel] G[roulx]. "Primauté du Spirituel, par Jacques Maritain [...]", L'Action française, vol. XVIII, $\mathrm{n}^{\circ} 3$ (septembre 1927), p. 188. [Cloutier 1997]

Compte rendu favorable par L. Groulx de ce livre paru en 1927 chez Plon à Paris (coll. "Le Roseau d'Or ") et publié à la suite de la condamnation par Rome de L'Action francaise de Paris. Dans son com- 
mentaire sur ce compte rendu, Y. Cloutier remarque l'« élasticité de la réception groulxienne : il appuie les positions de Maritain tout en spécifiant que le philosophe ne visait pas les catholiques de L'Action franfaise [...] » [Cloutier 1997, 402-403]. L. Groulx assure que le livre rassurera l'esprit et la foi de ceux qui ont été troublés par les décisions du Saint-siège concernant la mise à l'Index du journal dirigé par C. Maurras.

A[rthur]. R[obert]. "Jacques Maritain. Primauté du Spirituel [...], Paris, librairie Plon, 1927 », Le Canada francais, vol. XV, $\mathrm{n}^{\circ} 2$ (octobre 1927), p. 156. [Cloutier 1995]

Elogieux compte rendu. L'auteur en conseille la lecture qui « ramènera à bon port les intelligences désemparées ». Maritain ne dit rien de nouveau, selon l'auteur, mais le dit avec originalité, conviction et personnalité : " son mérite est d'avoir fait remonter à la surface des vérités nécessaires, en train de couler à pic $"$.

ROBER'T, Arthur. "Pourquoi Rome a parlé », Le Canada franfais, vol. XV, $\mathrm{n}^{\circ} 7$ (mars 1928), p. 458-467. [Cloutier 1995]

Long compte rendu de cet ouvrage collectif paru en 1927 (Paris, Éditions Spes), dans lequel Maritain signe un texte intitulé «Le sens de la condamnation». Cet article d'A. Robert donnera lieu aux remerciements et félicitations du Cardinal Gaspari au directeur du $\mathrm{Ca}$ nada français (XV, 9, mai 1928, p. 655) [Cloutier 1995]. Le ton de l'introduction laisse comprendre que le problème qui déchire la France ne se pose tout simplement pas au Québec. L'auteur espère que le volume convaincra enfin les sceptiques, mais souligne que le problème n'est « au fond pas compliqué du tout, mais que les passions, les intérêts se plaisent à [l']obscurcir au grand préjudice de la religion elle-même" (458). L'auteur comprend la sympathie de certains catholi- 
ques " amis de l'ordre » pour L'Action française, mais note que l'alliance est paradoxale et pose un cas de conscience, parce que les chefs de L'Action française sont non-croyants (460). Il souligne le prestige des auteurs (Maritain est ce « philosophe bien connu, l'un des maîtres les plus brillants de l'université catholique de $\mathrm{Pa}$ ris »), sans cacher leurs sympathies passées pour L'Action française (459). En conclusion, le recenseur écrit : "Notre intention en écrivant ces pages n'a pas été de chercher querelle d'[A]llemands. Nous avons tout simplement voulu contribuer [a] faire connaître un ouvrage dont le Saint-Père lui-même a parlé en termes très élogieux. [...] L'Université Laval, fière de suivre à la lettre les moindres directions pontificales, est heureuse, dans les pénibles circonstances actuelles, de dire respectueusement au Pape [...] qu'elle comprend plus que jamais pourquoi Rome a parlé.» (467)

\section{A[rthur]. R[obert]. « B. Bernadot, P. Doncœur, E. Lajeunie [...], Jacques Maritain, Clairvoyance de Rome [...], Éditions Spes, Paris, 1929 », Le Canada français, vol. XVII, n 6 (février 1930), p. 428. [Cloutier 1995]}

Les auteurs de Pourquoi Rome a parlé répondent dans ce nouvel ouvrage aux critiques qui leur ont été adressées. De nouveau, Maritain reçoit des éloges dans la suite de la polémique autour de L'Action française.

G.L. "Jacques Maritain. - Éléments de Pbilosopbie. II. L'Ordre des Concepts. I. Petite Logique (Logique formelle). Huitième édition revue et corrigée, Paris, Pierre Téqui, [...], 1933 », Revue de l'Université d'Ottawa, IV, vol. 3 (1934), p. 73*_74*.

Compte rendu favorable. 
LONGPRÉ, Anselme. [notice sur Antimoderne dans] $L a$ pensée catholique, Montréal, Éditions du Devoir, 1936, p. 158.

Ce livre est un «essai bibliographique d'études religieuse » (7) dans lequel plusieurs ouvrages de Maritain sont répertoriés et commentés. Antimoderne (1922) apparait dans le chapitre sur "la Philosophie », section " ouvrages d'introduction ». "Livre plein d'idées et d'idées fières », commente l'auteur.

- - [notice sur Art et scolastique dans] La pensée catbolique, Montréal, Éditions du Devoir, 1936, p. 149.

Art et scolastique (Paris, L'Art catholique, 1920) apparait dans le chapitre sur « l'art religieux ». « Le plus important ouvrage sur la théorie de l'art, unique en son genre ».

-. [notice sur Distinguer pour unir ou les Degrés du savoir dans] La pensée catbolique, Montréal, Éditions du Devoir, 1936, p. 164.

Cet ouvrage, paru à Paris chez Desclée de Brouwer en 1932, est recensé dans le chapitre sur « la Philosophie », section "traités sur différentes parties de la philosophie ». L'auteur affirme : « avec le "Dieu" de GarrigouLagrange, ce livre est l'ouvrage de philosophie le plus important de notre temps et classe définitivement Maritain parmi les plus grands philosophes de l'humanité. »

- [notice sur Le Docteur Angélique dans] La pensée catholique, Montréal, Éditions du Devoir, 1936, p. 167.

Cet ouvrage sur saint Thomas, paru à Paris chez Paul Hartmann en 1929, apparaît ici dans le chapitre sur « la Philosophie », section « quelques lectures historiques ». «Édition accessible et tout à fait remarquable d'une œuvre d'une haute portée intellectuelle. Apôtre autant 
que philosophe, J. Maritain s'est donné cette noble mission de rappeler l'actualité et la pérennité du thomisme $[\ldots] »$.

- [notice sur Introduction à la pbilosopbie dans] La pensée catholique, Montréal, Éditions du Devoir, 1936, p. 157.

Recension d'Éléments de philosophie (1920) dans le chapitre sur «la Philosophie», section " ouvrages d'introduction ». «Ouvrage indispensable. Livre classique, pour les étudiants et pour les maîtres ».

-. [notice sur Primauté du spirituel dans] La pensée catholique, Montréal, Éditions du Devoir, 1936, p. 123.

Primauté du spirituel (1927) est recensé dans le chapitre "Sociologie et action catholique ». "L'un des plus importants ouvrages de notre temps. À l'occasion de la crise de L'Action française de Paris, l'auteur a traité d'une façon magistrale de la connexion du spirituel et du temporel, du doctrinal et du politique. [...] Tous les hommes d'Action catholique doivent méditer cet ouvrage. »

- - [notice sur Réflexions sur l'intelligence et sur sa vie propre dans] La pensée catholique, Montréal, Éditions du Devoir, 1936, p. 161.

Cet ouvrage paru à Paris à la Nouvelle Librairie Nationale (1924) est recensé ici dans le chapitre sur « la Philosophie », section « traités sur différentes parties de la philosophie ». Selon l'auteur, il « [...] présente au nom du réalisme thomiste la plus ferme critique de l'erreur idéaliste, principe foncier des maux dont souffrent les esprits aujourd'hui ».

- - [notice sur Théonas dans] La pensée catholique, Montréal, Éditions du Devoir, 1936, p. 161.

Sur Théonas ou les entretiens d'un sage et de deux philosophes sur diverses matières inégalement actuelles (Paris, Nouvelle 
Librairie Nationale, 1921). Dans le chapitre sur «la Philosophie », section « traités sur différentes parties de la philosophie ». «Sur le ton d'une libre conversation, l'auteur traite de quelques problèmes métaphysiques les plus étroitement liés à la vie de notre époque $\%$.

CHARBONNEAU, Robert. " "Lettre sur l'Indépendance" ", La Relève, $2^{\mathrm{e}}$ série, $\mathrm{n}^{\text {os }}$ 9-10 (mai-juin 1936), p. 261-262.

Maritain publie la Lettre sur l'indépendance en 1935 à Paris (Desclée de Brouwer, coll. « Courrier des Iles »), à la suite des protestations qu'avaient suscitées dans les milieux catholiques sa participation à Vendredi, hebdomadaire indépendant de gauche. R. Charbonneau s'intéresse surtout ici à l'indépendance affirmée par Maritain à l'égard des partis de gauche et de droite, expliquant les circonstances de la publication. Il souligne aussi que selon Maritain, l'intervention des catholiques dans la sphère politique doit se faire non pas en tant que membres de l'Église, mais «à titre de membres chrétiens d'une cité terrestre particulière » (262). Cette indépendance revendiquée par Maritain est avant tout, pour $\mathrm{R}$. Charbonneau, un engagement à ouvrir le dialogue avec les idées de gauche.

LAURENDEAU, André. « Le dernier livre de Jacques Maritain : "Humanisme intégral" ", L'Action nationale, vol. IX, no 3 (mars 1937), p. 175-176.

Compte rendu d'Humanisme intégral. Problemes temporels et spirituels d'une nouvelle chrétienté, paru en 1936 à Paris chez Fernand Aubier/Éditions Montaigne. Le livre est décrit comme "l'une des œuvres capitales de l'époque » (175). A. Laurendeau exprime, malgré certaines réserves, sa reconnaissance envers Maritain pour cet ouvrage. "Nous aurons à maintes reprises l'occasion d'y revenir et de nous en inspirer », conclut-t-il (176). 
PRESSÉ, Fr. Léo. «Les Juifs parmi les nations », Les Carnets du théologue, III' année, $\mathrm{n}^{\circ} 3$ (juin 1938), p. 121-122. [Houde 1973-II, 215]

Recension d'un article paru dans la Vie intellectuelle du 25 février 1938 et dans lequel Maritain montre l'inadmissibilité de l'antisémitisme pour les catholiques.

SABY, P. Pierre. «Le Chrétien et le monde », Les Carnets $d u$ théologue, III $^{\mathrm{e}}$ année, $\mathrm{n}^{\circ} 3$ (juin 1938), p. 122-123. [Houde 1973-II, 215]

Recension et recommandation d'un article paru dans la Vie intellectuelle du 10 avril 1938.

COUSINEAU, Jacques. "Jacques Maritain, Le Crépuscule de la civilisation», Relations, $\mathrm{n}^{\circ} 3$ (mars 1941), p. 83. [Houde 1973-II, 216]

L'ouvrage, d'abord publié en 1939 à Paris aux Éditions Les Nouvelles Lettres, est repris en 1941 aux éditions de l'Arbre à Montréal. C'est de cette réédition que J. Cousineau fait un compte rendu fort élogieux.

ROY, Louis-Philippe. "À Travers le Désastre », L'Action catholique, lundi 24 mars 1941, p. 4. [Houde 1973-II, 216]

Recension critique d'À travers le désastre (New York, Maison française, 1941), livre portant sur la guerre et vendu à la Librairie d'action catholique. Malgré les désaccords du journaliste (et du journal) avec Maritain au sujet de la guerre d'Espagne et du régime de Vichy, Roy propose une lecture favorable du livre, car celuici explique les raisons de la capitulation française sans trop accabler le maréchal Pétain. L'auteur annonce d'autres articles à venir sur le même sujet (voir les deux notices suivantes). 
—. "Maritain et Vichy", L'Action catbolique, jeudi 27 mars 1941, p. 4.

Suite de la recension précédente. L.-P. Roy est tendre avec Maritain, car celui-ci ne condamne pas en bloc Pétain et le gouvernement de Vichy ; le philosophe apparaît cependant comme «trop sévère » envers le maréchal.

- " Maritain, de Gaulle et la France ", L'Action catholique, vendredi 4 avril 1941, p. 4.

Suite de la recension précédente ; l'auteur y examine la position de Maritain vis-à-vis du général de Gaulle et félicite le philosophe de garder une attitude nuancée, plaçant le sort de la France au-dessus de l'adhésion à un parti.

$\mathrm{J}$ [ean]-Ch[arles] $\mathrm{H}$ [arvey]. «Chronique des livres : Témoignage sur la situation actuelle en France par un dirigeant d'action catholique ", Le Jour, samedi 28 février 1942, p. 2.

J.-Ch. Harvey mentionne la préface de Maritain et en fait l'éloge.

SYLVESTRE, Guy. "Confession de foi ", Le Droit, samedi 11 avril 1942.

Ce «testament spirituel » est paru à New York, Maison française, 1941. La recension insiste sur la position nuancée de Maritain, qui s'oppose autant aux anti-religieux qu'aux bien-pensants. G. Sylvestre reprend les propos par lesquels Maritain positionne sa philosophie en regard de la science moderne : elle n'y est pas opposée, mais explore une autre sphère de la connaissance, où elle accède par le biais de l'« irrationnel " et du «surrationnel ». Le compte rendu se termine sur un hymne à l'amour : sans amour, toute chose - y compris les progrès scientifiques et la foi religieuse - «sert à rendre les hommes plus mauvais et plus malheureux $»$. 
G. P. «Jacques Maritain, Crépuscule de la civilisation», Les

Carnets viatoriens, VIII ${ }^{\mathrm{e}}$ année, $\mathrm{n}^{\circ} 3$ (juillet 1942), p. 231-232. [Houde 1973-II, 216]

Il s'agit d'un compte rendu peu sympathique, même si son auteur n'attaque pas de front les positions de Maritain.

«Autour et alentour. Maritain et Saint-Exupéry 》, $\mathrm{Le} C \mathrm{Ca}$ nada, mardi 22 décembre 1942, p. 2.

Brève présentation de l'échange entre les deux écrivains publié dans les pages du journal.

LE MOYNE, Jean. «Les Juifs - Par Paul Claudel, Jacques Maritain et plusieurs autres distingués écrivains », $\mathrm{Le} \mathrm{Ca}$ nada, lundi 26 avril 1943, p. 4.

Recension faite à l'occasion d'une réimpression aux Éditions de l'Arbre d'un ouvrage collectif d'abord paru à Paris chez Plon (coll. « Présences », 1937). L'auteur ne rend pas compte de chacun des articles, mais reprend les idées générales, en faisant mention spéciale à la contribution de Maritain.

SARAGON. «Le drame des lettres françaises sous l'occupation : trahison ou silence ", Le Canada, lundi 26 juillet 1943, p. 4.

Présentée comme un compte rendu d' $A$ travers le désastre, cette colonne contient surtout des propos sur la collaboration et les problèmes de l'édition et de la censure en France occupée. Le cas de la publication du livre de Maritain, d'abord à l'étranger puis en France aux éditions de Minuit, est cité en exemple. Extrait de Résistance, journal français clandestin.

LE MOYNE, Jean. «Revue des revues », Le Canada, lundi 20 septembre 1943, p. 5. 
Recension de l'article de Maritain paru dans La Revue dominicaine, «Sur le jugement artistique », vol. XLIX, nº (septembre 1943), p. 65-68.

"Livres et revues. Des témoignages chrétiens ", Le Devoir, 20 novembre 1943 , p. 8.

Dans une chronique de la page littéraire, article sur la collection «Civilisation » dirigée par Jacques Maritain à la Maison française d'éditions de New York. L'auteur présente un certain nombre d'ouvrages de la collection et cite l'avant-propos de Maritain expliquant les objectifs de la collection.

SAINTONGE, Frédéric, "Jacques Maritain : Principes d'une politique bumaniste, New-York, Éditions de la Maison Française, 1944 », Relations, n 46 (octobre 1944), p. 277-278. [Houde 1973-II, 216]

L'auteur donne un compte rendu élogieux où Maritain est présenté comme un guide pour les démocrates.

Fra. "Jacques Maritain, Humanisme intégral, édité à Paris (Fernand Aubier), réimprimé en Canada par les Éditions de l'Arbre [...] ", Le Canada français, vol. XXXII, n 10 (juin 1945), p. 796-797. [Cloutier 2002]

Maritain est ambassadeur au Vatican au moment de la réimpression par les Éditions de l'Arbre de Humanisme intégral (1945). Éloges et recommandation des jugements de Maritain sur « les grandes expériences humanistes du passé ». «Sa doctrine sûre est une sauvegarde pour l'esprit qui veut être à la fois chrétien et moderne. » 
LAMARCHE, Ant. "Jacques Maritain, "Humanisme intégral". Les Éditions de l'Arbre. Montréal, 1944 [...] », La Revue dominicaine, vol. LI, no 10 (octobre 1945), p. 188. [Cloutier 2002]

L'auteur rappelle la réception controversée d'Humanisme intégral lors de sa parution en 1936 (en Europe et en Amérique). La recension est très favorable. Non seulement le livre a le mérite de "piquer notre apathie intellectuelle », mais il fait « le procès des idéologies qui ont conduit notre siècle à la ruine » et exalte «l'efficacité des principes thomistes dans la reconstruction du monde $»$. Une nuance : tout n'est pas que clarté dans Humanisme intégral.

GIRARD, René. «Compte rendu de la Correspondance avec le R.P. Garrigou-Lagrange à propos de Lamennais et Maritain, par Jules Meinvielle », Relations, $\mathrm{n}^{\circ} 88$ (avril 1948), p. 127. [Houde 1973-II, 217]

Compte rendu de 10 lignes sur ce livre dont l'auteur affirme que Maritain renouvelle les erreurs de Lamennais, condamnées par l'Église. Dans ses réponses, Garrigou-Lagrange admet qu'il y a là du vrai, mais reste plus nuancé.

\subsection{Recensions d'ouvrages de Raïsa Maritain (par ordre chronologique $)^{26}$}

SYLVESTRE, Guy. "Lettre de nuit. La Vie donnée », La Revue dominicaine, vol. XLVI, $\mathrm{n}^{\circ} 9$ (septembre 1940), p. 103104. [Sylvestre 1983]

Recension du recueil de poèmes paru en 1939 à Paris chez Desclée de Brouwer (collection «Les Îles »), qui sera réédité à Montréal aux Éditions de l'Arbre en 1943 
-. "Les Grandes Amitiés », Le Droit, samedi 15 novembre 1941. [Sylvestre 1983]

Paru à New York, Maison française, 1941.

RAYMOND, Marcel. «Les Grandes Amitiés par Raïssa Maritain ", La Nouvelle Relève, vol. I, n³ (décembre 1941), p. 179-182.

Après un bref survol des cuvres de Raïssa Maritain connues au Canada, M. Raymond donne un long et élogieux compte rendu de cet ouvrage de souvenirs qui est aussi, remarque-t-il, un document précieux sur le renouveau catholique en France au début du $\mathrm{XX}^{\mathrm{c}}$ siècle. Suit un résumé centré sur la biographie de Raïssa Maritain.

D'APOLLONIA, Luigi. «Raïssa Maritain : Les Grandes Amitiés. - New-York, Éditions de la Maison Française, 1941 [...] », Relations, no 15 (mars 1942), p. 83-84. [Houde 1973-II, 216]

Raconte les étapes successives de la « délivrance de tous les positivismes » qui menèrent Raïssa et Jacques Maritain vers la conversion au catholicisme.

BEAULIEU, Simone-A. «Chagall par Raïssa Maritain », La Nouvelle Relève, vol. II, no 8 (juillet-août 1943), p. 507-508.

Recension de ce livre illustré paru à la Maison française (New York, 1943).

SYLVESTRE, Guy. "Raïssa Maritain : Marc Chagall, illustré, Maison française, New York, 1943 ", Gants du ciel, $\mathrm{n}^{\circ} 1$ (septembre 1943), p. 113-114. [Sylvestre 1983, 113] 
BEAULIEU, Simone. "Les Furres nouvelles, III, Maison Française, New York, 1943 ", Gants du ciel, n 2 (décembre 1943), p. 99-100.

Recension d'un ouvrage collectif contenant un texte de Raïssa Maritain. Éloge des pages de Raïssa, « Jours de Soleil en France », des souvenirs de Georges Rouault, Éric Satie et Georges Auric.

LE MOYNE, Jean. "Poèmes. "Lettre de nuit", "La vie donnée", par Raïssa Maritain - 1 vol. aux Éditions de l'Arbre ", Le Canada, lundi 3 janvier 1944, p. 5.

Le recueil est réédité à Montréal aux Éditions de l'Arbre en 1943. Cette recension a été reproduite dans les Écrits du Canada franfais, 49 (1983), p. 83-87.

RAYMOND, Marcel. «Les Aventures de la grâce, par Raïssa Maritain ", La Nouvelle Relève, vol. IV, $\mathrm{n}^{\circ} 1$ (avril 1945), p. 64-68.

Tome II des Grandes Amitiés, paru en 1941 à New York (Maison française).

-_. "Les CEuvres nouvelles», La Nouvelle Relève, vol. IV, $\mathrm{n}^{\circ} 1$ (avril 1945), p. 71-75.

Recension d'un ouvrage collectif contenant un texte de Raïssa.

\section{4. Études sur Jacques et Raïssa Maritain au Québec (1920-1950) (ordre alphabétique)}

Cette section offre le relevé le plus complet possible des études et articles approfondis sur Maritain publiés au Québec entre 1920 et 1950 . Nous y incluons également les travaux d'histoire, de littérature ou de sociologie, québécois ou non, qui documentent la question de l'influence de Maritain au Québec et au Canada français pendant cette période. Nous 
laissons de côté les travaux portant sur Maritain au Canada anglais, sauf lorsqu'ils contiennent des informations susceptibles d'éclairer ses relations avec le Québec.

Nous avons pris le parti de ne pas retenir les nombreux textes québécois de la période qui se réfèrent à Maritain sans en faire leur sujet principal ; leur inclusion aurait pratiquement doublé l'ampleur de la présente bibliographie. Il est indéniable, en effet, que Maritain fait partie du paysage intellectuel québécois des années 1930 à 1950. Quelques exceptions ont retenu notre attention : on trouvera un petit nombre d'articles pour lesquels la pensée de Maritain constitue l'une des influences principales et affichées. Il est entendu qu'il entre dans ces choix une part de subjectivité. Nous indiquons ces notices par un astérisque et les accompagnons d'une note explicative.

ALLARD, Jean-Louis. «Le rayonnement de Jacques Maritain au Canada français », Cabiers Jacques Maritain, $\mathrm{n}^{\circ} 31$ (décembre 1995), p. 41-50.

AMYOT, Éric. Le Québec entre Pétain et de Gaulle. Vichy, la France Libre et les Canadiens francais, 1940-1945, Montréal, Fides, 1999.

Quelques passages sur l'influence exercée par Jacques Maritain sur l'opinion canadienne vis-à-vis du gouvernement de Vichy et de la France Libre.

ANGERS, Stéphanie et Gérard FABRE. Échanges intellectuels entre la France et le Québec, 1930-2000: les réseaux de la revue Esprit avec La Relève, Cité libre, Parti pris et Possibles, Québec, PUL, 2004.

Le chapitre 2 , intitulé « La Relève, au cœur des échanges avec les intellectuels européens " (17-46), traite des relations entre la revue montréalaise et Maritain, lequel aurait joué les intermédiaires entre La Relève et Mou- 
nier. En plus de recenser les contributions de Maritain à La Relève, les auteurs font état des controverses suscitées par ses prises de position lors des guerres d'Éthiopie et d'Espagne, et de l'importance accordée à son thomisme renouvelé dans le cours classique de la génération de La Relève. Selon les auteurs, La Relève n'aurait pu « développer et légitimer son projet de rénovation du catholicisme et de la vie spirituelle » sans les échanges avec les auteurs européens, dont Maritain.

ANGERS-FABRE, Stéphanie. "Le versant canadienfrançais de la génération "non-conformiste" européenne des années trente : la revue La Relève", Recherches sociographiques, XLIII, 1 (2002), p. 133-148.

ARMOUR, Leslie. «Maritain, Canada, and the Scholastic Tradition ", "Maritain and Gilson in Canada [dossier] ", Maritain Studies/Études maritainiennes, vol. 15 (1999), p. 5269.

Nous incluons les articles de ce numéro spécial à la bibliographie pour l'information du lecteur, même s'il est indiqué clairement que les relations de Maritain avec le Canada français appartiennent à un tout autre rayon (" a wholly other shelf ", écrit L. Dewan dans le même numéro, p. 19). L. Armour examine les différentes écoles du thomisme au Canada (français et anglais) à l'époque des visites de Maritain, et son inscription dans les débats philosophiques, en plus d'étudier l'influence élargie de Maritain au Canada.

BAAS, Émile. "Jacques Maritain et la charité ", La Nouvelle Relève, vol. II, n² (décembre 1942), p. 87-89.

Dans un numéro hommage à Jacques Maritain. 
BASTIEN, Hermas. « Figure de philosophe. Jacques Maritain ", L'Action française, vol. XIII (janvier 1925), p. 54-56.

Note biographique où Maritain est désigné comme «Le célèbre professeur de philosophie de l'Institut catholique de Paris [...]» (54) et comme le "plus brillant maitre actuel » du thomisme en France (55). Bastien mentionne le travail de Maritain comme chroniqueur de philosophie à la Revue universelle (on suppose que le lien de cette revue avec L'Action franfaise de Paris est connu des lecteurs) (55).

-. "Jacques Maritain", dans Itinéraires philosopbiques, Montréal, Librairie d'Action canadienne-française, 1929, p. 119-136.

Ce chapitre offre un récit du parcours biographique de Maritain, centré sur l'époque de sa conversion et ses premières années de carrière.

*_. Rencontres avec moi-même, BAnQ, Fonds MSS-257, boîte $1,478 \mathrm{p}$.

Cette autobiographie non publiée offre un bon exemple d'un auteur de la génération précédant celle dite «de La Relève » : Bastien, actif dans les milieux intellectuels dès les années 1920, s'est aussi intéressé vivement à Maritain. Dans ce texte autobiographique, il reconnaît son influence et signale les ouvrages dans lesquels il a voulu dialoguer avec lui. Bastien s'est éloigné de Maritain à partir du « virage » à gauche de ce dernier au milieu des années 1930, tout en continuant le dialogue.

BEAULIEU, Paul. «Le Pèlerinage vers l'absolu », $L a$ Nowvelle Relève, vol. I, n 5 (février 1942), p. 273-284. [Houde 1973-II, 216]

Étude sur Les Grandes Amitiés de Rä̈ssa Maritain (New York, Maison française, 1941). 
—. «La chaleur de l'accueil chez Jacques et Raissa Maritain », Écrits du Canada français, n" 49 (1983), p. 7-16.

Témoignage et souvenirs incluant une chronologie des rencontres et des rapports entre les Maritain et l'équipe de La Relève, une interprétation des diverses polémiques entourant les positions politiques de Maritain et des précisions sur les publications de Jacques et Raïssa Maritain en Amérique.

BÉLANGER, M. «Monsieur Maritain », Revue de l'Université d'Ottawa, XIII (octobre 1943), p. 444-447. [Houde 1973-II, 216]

BIRON, Michel. L'Absence du maître, Montréal, PUM, 2000 (coll. «Socius »), p. 49-68.

Quelques pages de cet ouvrage établissent un lien entre les positions de Maritain sur la poésie moderne et l'écriture «liminaire » d'Hector de Saint-Denys Garneau. Citant Art et scolastique, M. Biron soutient qu'" À défaut d'une esthétique, [Maritain] laisse le poète aux prises avec un malaise dont Garneau ne parviendra jamais à se libérer. Le seul moyen de se prémunir contre le péché d'orgueil et d'assumer la position paradoxale définie par Maritain (être un artiste inconscient de son art), c'est de soustraire l'écriture à sa mise en scène sociale. » (59-60).

BLANCHE'T, Charles. «La correspondance Étienne Gilson-Jacques Maritain (1923-1971)", Cabiers Jacques Maritain, $\mathrm{n}^{\circ} 23$ (octobre 1991), p. 43-64.

C'est grâce à É. Gilson, l'un des fondateurs du Pontifical Institute of Mediaeval Studies de Toronto dès 1925, que Maritain sera invité à donner des conférences au Canada, puis au Québec. 
BOILY, Hélène. « Entre la raison et l'expérience : pour une approche des fondements intellectuels de la pensée artistique au Québec dans les années vingt ", mémoire de maîtrise en études des arts, UQAM, 1998.

H. Boily étudie la pénétration de la philosophie néothomiste, et plus particulièrement des idées esthétiques de Maritain, dans les milieux artistiques et intellectuels québécois des années 1920 . Son étude fait ressortir la parenté d'idées entre Maritain et plusieurs intellectuels québécois, parmi lesquels Louis Dantin, Arthur Laurendeau et Hermas Bastien. C'est, à notre connaissance, la seule étude qui documente l'influence de Maritain dès les années 1920 .

BOIS, Bérengère. «Jacques Maritain : controverses et influences 1930-1960», mémoire de maîtrise en histoire contemporaine, Université Jean Moulin, Lyon 3, Faculté des lettres et communications, 1995-1996.

Porte surtout sur la controverse philosophique qui oppose Maritain à C. De Koninck.

BOURNEUF, Roland. Saint-Denys Gameau et ses lectures européennes, Québec, PUL, 1969 (coll. «Vie des lettres canadiennes ', $\mathrm{n}^{\circ}$ 6).

Cette étude présente plusieurs références à Maritain et examine l'influence du philosophe sur le poète.

BRAULT, Jean-Rémi. "Souvenirs de Jacques et Raïssa Maritain ", Les Cabiers d'bistoire du Québec au XX' siècle, $\mathrm{n}^{\circ} 6$ (automne 1996), p.131-139.

J.-R. Brault raconte comment il a essayé, en 1965, d'acheter un fonds d'œuvres des Maritain et de travaux consacrés à leur pensée afin de démarrer un centre de documentation Jacques et Raïssa Maritain au Collège de Sainte-Thérèse. Le projet restera sans suite, 
signe qu'après le rapport Parent, le thomisme et la philosophie de Maritain paraissent appartenir à une autre époque.

«La célébration du cinquantenaire d'Humanisme intégral à Ottawa ", Études Maritainiennes/Maritain Studies, $\mathrm{n}^{\circ} 3$ (avril 1987).

*CHARBONNEAU, Robert. «Notes sur la jeunesse. Jeunesse et régime », La Relève, $2^{\circ}$ série, $\mathrm{n}^{\circ} 4$ (décembre 1935), p. 99-103.

Dans ce texte sur la jeunesse moderne, R. Charbonneau intègre la distinction maritainienne entre l'agir $e n$ chrétien et l'agir en tant que chrétien, et se réfère à Maritain pour affirmer l'incompatibilité du système économique libéral et des valeurs chrétiennes.

-. "Hommage », La Nouvelle Relève, vol. II, n 2 (décembre 1942), p. 65.

Introduction d'un numéro spécial consacré à Jacques Maritain.

*__. Connaissance du personnage, Montréal, L'Arbre, 1944.

R. Charbonneau fait de François Mauriac, auteur du Romancier et ses personnages (Corrêa Buchet-Chastel, 1933), la référence principale de ce recueil d'essais sur le roman. Cependant, les positions de Maritain sur la création artistique, notamment en ce qui concerne la ressemblance de l'œuvre avec l'âme de son créateur, de même que ses opinions sur la responsabilité morale du romancier, ont manifestement eu beaucoup d'importance pour le développement de la théorie romanesque de R. Charbonneau. Cela n'est pas sans donner lieu à certaines des ambiguïtés de ce recueil. En effet, les deux "maîtres" de Charbonneau défendent des points de vue divergents (exposées dans Art et scolasti- 
que (1920), puis Frontières de la poésie (1935) pour Maritain, et dans Le Roman (1928) pour Mauriac).

-. "Rencontre avec Jacques Maritain », Écrits du Canada français, $\mathrm{n}^{\circ} 49$ (1983), p. 41-42.

R. Charbonneau affirme devoir son attachement au thomisme à Maritain plus qu'à l'enseignement reçu au Collège Sainte-Marie ; il déplore par ailleurs avoir mis " trop de temps à [se] détacher » de cette influence. Texte non daté.

CHARBONNEAU, Robert et Claude HURTUBISE. «Ce que nous devons à Jacques Maritain ", La Nowvelle Relève, vol. II, no 2 (décembre 1942), p. 70-71.

Dans un numéro spécial consacré au philosophe, les auteurs rappellent leur découverte de Maritain au collège, par la lecture de Primauté du spirituel, Trois Réformateurs et Art et scolastique, puis la rencontre de l'homme en 1934. Maritain « rétablissait les contacts de la pensée catholique avec les avant-gardes ", c'est pourquoi il a tant plu aux jeunes animateurs de La Relève.

CHARLAND, Raymond-Marie. "Puis-je lire des romans?", La Revue dominicaine, vol. XIIII, n 5 (mai 1937), p. $228-234^{27}$.

L'auteur tente de répondre à la question suivante : quels romans sont bons, lesquels sont mauvais? La question de la responsabilité du romancier envers les âmes de ses lecteurs est posée (229). R.-M. Charland prend appui sur Maritain (Art et scolastique) : l'art est souverain dans son domaine propre, mais par le sujet et dans le sujet il est subordonné au bien du sujet (230). Plus loin, on trouve une autre citation d'Art et scolastique: " la question n'est pas de savoir si un romancier peut ou non peindte tel ou tel aspect du mal. La question essentielle est de savoir à quelle hauteuril se tient pour faire 
cette peinture, et si son art et son cœur sont assez purs

[...] pour le faire sans connivence. » (232)

CLOUTIER, Yvan. «De quelques usages québécois de Maritain : la génération de La Relève », dans Benoît Melançon et Pierre Popovic (dir.), Saint-Denys Gameau et La Relève, Fides-CETUQ, 1995, p. 62-66.

—. «L'influence de Maritain : un déterminant de la réception de Vatican II au Québec », dans Gilles Routhier (dir.), L'Église canadienne et Vatican II, Montréal, Fides, 1997, p. 397-411.

En introduction au recueil, Gilles Routhier rappelle que " [d]ans cet ensemble consacré à l'Église canadienne et Vatican II, poser la figure de Maritain ne semble pas immédiatement évident. Cela s'impose pourtant [...]. Les évêques qui participaient au concile étaient des gens de leur époque et de leur génération. Leurs représentations avaient été formées par les débats de leurs années de formation et de ministère. [...] Comment faire alors l'impasse sur les courants de pensée majeurs qui avaient marqué leur temps de formation ? À cet égard, la figure de Maritain, relayée par la suite par les écrits de Mounier et l'équipe de la revue Esprit, nous semble incontournable tant elle a marqué les débats québécois des années 1920 à 1940. Faire appel à la figure de Maritain, c'est situer Vatican II non pas comme une génération spontanée, mais dans une lignée et comme un moment particulier dans une série d'événements qui jalonnent l'histoire des idées au cours des années préconciliaires. » (21-22)

L'hypothèse de Cloutier est que « la réception positive de Maritain (conception du monde et figure) dans les années 1920, 1930 et 1940 aurait contribué à légitimer une parole du laïcat » et donc à rendre possible la réception positive, plusieurs années plus tard, de Vatican 
II (398). Selon lui, « l'ambiguïté de la thèse maritainienne se prête à des usages très divers, voire opposés ». Par exemple, la notion d'humanisme intégral « servit de visa idéologique pour justifier l'autonomie de l'action des laïcs mais aussi l'action censoriale » (399), ce qui fait écho aux propos de Pierre Hébert (2004, voir notice ci-dessous) tout en y apportant quelque nuance. Par ailleurs, l'influence de Maritain aura touché deux générations avec des positions très différentes - de L'Action française à la France Libre (400). L'auteur distingue trois moments dans la réception de Maritain au Québec. Un "premier arrimage» se fait dans les années 1920 auprès du clergé et de « lecteurs, intellectuels catholiques, d'orientations et de milieux divers " (401403). Il rejoint ensuite un " public élargi » avec les conférences de 1934 qui créent un effet de mode (403), alors que « []] réputation de Maritain est confirmée par les institutions hôtes montréalaises [...]» (404). Enfin, des «zélateurs » de Maritain - La Relève et les éditions de l'Arbre (405-408), « de jeunes intellectuels dont l'influence est déterminante dans le journalisme et dans l'édition " (408-409), ainsi que les dominicains et leur sphère d'influence (409) - répandent ses idées.

- - "Maritain, Mounier et le Québec : une tutelle éditoriale ", dans Claude Hauser et Yvan Lamonde (dir.), Regards croisés entre le Jura, la Suisse romande et le Québec, Québec/ Porrentruy, Presses de l'Université Laval/Office du patrimoine et de la culture de la République et Canton du Jura, 2002, p. 223-235.

COHEN, Gustave. «Appendice. Jacques Maritain, notre nouvel ambassadeur au Vatican ", dans Ceux que j'ai connus, Montréal, Éditions de l'Arbre, 1946, p. 201-209. [Houde 1973-II, 217] 
G. Cohen rappelle le rôle joué par Maritain durant la guerre comme ambassadeur officieux de la France en Amérique, de même que la fondation de l'École Libre des Hautes Études de New York.

CORMIER, Guy. "Jacques Maritain », La Presse, $1^{\text {er }}$ mai 1973.

Témoignage d'un ancien de Cité libre.

CUNNINGHAM, Henri-Paul. Coup d'xil sur l'bistoire de la faculté de pbilosopbie, Québec, Publications de l'Université Laval, s. d., s. p. [Cloutier 1997]

À propos des conférences de Maritain à Québec et de son influence là-bas, « certaine » selon Y. Cloutier [1997, 405].

"Dans l'Église et dans l'ordre », La Revue dominicaine, vol. XXVII, no 8 (août 1921), p. 246-247.

Dans une chronique sur l'actualité des études thomistes, on trouve une section intitulée « Jacques Maritain ». "Toujours à propos de la renaissance thomiste", l'auteur donne une citation de Léon Daudet dans L'Action franfaise, lequel loue les contributions de Maritain à la Revue universelle, notamment en opposition au criticisme allemand.

DÉCARIE, Vianney. «Témoignage. Jacques Maritain », Le Devoir, 3 mai 1973.

Souvenirs et témoignages sur Maritain, son influence, son apport au Québec.

*DE KONINCK, Charles. « Réflexions sur le problème de l'Indéterminisme », Revue thomiste, $45^{\mathrm{e}}$ année, tome XIIII (1937), p. 227-252 et 393-409. [Cloutier 2002, 231]

Article contre le déterminisme et fondant une critique des sciences exactes qui reposent sur ce principe. 
L'auteur renvoie à Maritain, notamment à Science et sagesse (p. 406 et 408).

De la primauté du bien commun contre les personnalistes. Extrait de la Semaine religieuse de Québec, 55 année (1942), nos 12, 13, 14 et 15, Québec, s.e., 1942.

Cette brochure lance une controverse opposant Charles De Koninck à Maritain [Houde 1973-II, 216]. Le texte sera repris en volume l'année suivante, dans une version plus étendue et accompagnée d'un autre essai, Le Principe de l'ordre nowveau (Québec/Montréal, Éditions de l'Université Laval/Fides, 1943). Le cardinal Villeneuve en signe alors la préface. Aussi « La Notion de bien commun ", L'Académie Canadienne Saint Thomas d'Aquin (12c session, les 14 et 15 octobre 1942), Québec, Imprimerie Franciscaine Missionnaire, 1945, p. 51108 [Houde 1973-II, 216].

Après avoir établi les distinctions entre le bien commun et le bien singulier des personnes, l'auteur s'attaque à ceux qui soutiennent que le bien des personnes est supérieur au bien commun, i.e. que le bien commun est bien en tant qu'il bénéficie à chacune des personnes (on comprend qu'il s'agit des « personnalistes »). Pour C. De Koninck, le bien commun inclut le bien des particuliers, mais il le dépasse : subordonner le bien commun à celui des personnes, c'est créer une " société, non pas d'hommes libres, mais de tyrans [...] où le chef éventuel n'est que le plus astucieux et le plus fort parmi les tyrans » (8), une société sans ordre. Il veut démontrer que les positions des personnalistes supposent une conception collectiviste de la société comme « entité séparable de ses membres " (20), conception qui instaure une tension entre la personne et la société. $\mathrm{Au}$ contraire, pour C. De Koninck, la société et l'ordre social sont, plus encore que chacune des personnes individuelles, à l'image de la perfection divine (20). L'auteur 
soutient enfin que " les personnalistes sont, au fond, d'accord avec ceux dont ils prétendent combattre les erreurs » : les individualistes et les totalitaristes.

Maritain, qui n'est jamais nommé par C. De Koninck, ne se serait pas senti visé par le livre [Angers et Fabre 2004, 37-38]. T. Eschmann prit néanmoins sa défense en 1945 (notice ci-dessous) ; la réplique de C. De Koninck laissera voir plus clairement les désaccords entre les deux philosophes (voir notice suivante).

- «In Defense of St. Thomas », Laval théologique et philosophique, vol. I, n 2 (1945), p. 9-109. [Houde 1973-II, 217]

Réponse à T. Eschmann (notice ci-dessous), qui prit la défense de Maritain après la publication de De la primauté du bien commun contre les personnalistes en 1942 (notice ci-dessus). C. De Koninck remarque deux réactions provoquées par son ouvrage de 1942 : certains ont voulu défendre Maritain qui était attaqué, alors que d'autres ont soutenu que ce n'était pas lui qu'on attaquait. Il rappelle qu'il n'a jamais nommé Maritain, mais surtout, il exprime le souhait que ce dernier parle pour lui-même dans cette affaire. Pour C. De Koninck, l'apparition de ces deux interprétations contradictoires prouve que Maritain n'a jamais donné de réponse claire, philosophique, au problème traité.

DEPRÉS, Louis. "Cette aventure divine : l'amitié ", $L a$ Releve, $2^{\mathrm{c}}$ série, $\mathrm{n}^{\circ} 7$ (mars 1936), p. 215-221.

Article portant sur l'amitié qui unit Maritain à E. Psichari. 
DEWAN, Lawrence. «Jacques Maritain and Toronto (A Visit to P.I.M.S.-S.M.C. Archives) ", "Maritain and Gilson in Canada [dossier] ", Maritain Studies/Études maritainiennes, vol. 15 (1999), p. 13-51.

L'auteur examine le contenu des archives du Pontifical Institute of Mediaeval Studies et du St. Michael's College de l'Université de Toronto. Ce fonds contient, entre autres documents, des lettres échangées entre Jacques Maritain, Étienne Gilson et Gerald B. Phelan, à partir desquelles l'auteur établit les détails de l'organisation, des dates et du contenu des cours donnés lors des visites de Maritain à Toronto (p. 15-50). On y trouve aussi des lettres de Maritain à divers correspondants québécois tels que Guy Sylvestre et Éva Thibaudeau, dont sont cités de larges extraits (p. 13, 17, 21, 23, 4041), ainsi que quelques indications sur le séjour de l'automne 1934 à Montréal et Ottawa (p. 21-22).

*DUBOIS, Fr. André-Émile. "Les "Institutions" dans la chrétienté nouvelle ", Les Carnets du théologue, III année, $\mathrm{n}^{\circ} 3$ (juin 1938), p. 85-97:

Dernier d'une série de trois articles étudiant respectivement les symptômes de la civilisation nouvelle, les caractéristiques des âmes dans cette civilisation, et ici, les institutions qui l'encadreront. Sans qu'il s'agisse à proprement parler d'études sur Maritain, les ouvrages et les conférences où il définit les contours de la « chrétienté nouvelle " paraissent en être l'une des inspirations premières ; chacun des articles, en particulier celui du Fr. Dubois, fourmille de références aux écrits de Maritain.

DUMAS, Paul. «Jacques Maritain au pays de Canada », Le Semeur, vol. XXX, n³ (novembre 1934), p. 44-49.

L'auteur fait une élogieuse présentation de Maritain : «L'un des plus magnifiques ambassadeurs que nous 
ait jamais envoyé [sic] la France », il représente « le type parfait de l'honnête personne de la nouvelle chrétienté ». Laissant de côté ses œuvres, P. Dumas veut « souligner quelques aspects de son enseignement ». Suit une synthèse des conférences de 1934, que l'auteur conclut en citant le mot de Maritain adressé aux jeunes nationalistes canadiens-français : «Contentez-vous d'exister », i.e., d'« Exister, existentiellement et essentiellement, en catholiques $\%$.

*___ «Le nationalisme des jeunes Canadiens-français", Joumées thomistes II (1937), p. 21-25.

L'auteur, membre des Jeune-Canada, a prononcé cette allocution aux Journées thomistes de 1936. Il fait appel à Maritain pour sa définition du nationalisme.

DURAND, Jean-Dominique. "La grande attaque de 1956 », Cabiers Jacques Maritain, no 30 (juin 1995), p. 2-31.

Brève référence à la polémique avec C. de Koninck, 1942.

DURELLI, Augusto-J. "L'exemple humain de Jacques Maritain », La Nowvelle Relève, vol. II, n² (décembre 1942), p. $72-86$.

Dans un numéro spécial consacré à Maritain. L'attitude de Maritain devant la guerre - son refus de fermer les yeux sur les injustices qu'elle déchaîne - offre un « exemple humain, un exemple d'humanisme intégral ». Ce texte rend hommage au philosophe qui descend dans l'arène politique pour défendre ce qu'il croit juste, en dépit de son dégoût. L'auteur passe en revue les combats successifs qu'a menés Maritain : de ses luttes contre les bourgeois qui l'accusaient de communisme en 1935, jusqu'à ses écrits de guerre. 
D[URELLI ${ }^{28}$, Augusto J. « Une nouvelle attaque contre Maritain ", Le Canada, lundi 24 mai 1943, p. 4.

Lettre au directeur du journal publiée sous la rubrique "Tribune libre " à la suite des attaques portées contre Maritain par Dom Jamet. L'auteur reprend et contredit un à un les arguments de Dom Jamet. À propos de l'influence exercée par Maritain en France avant la guerre, il rappelle que « Sept, Temps Présent, La Vie Intellectuelle, La Vie Spirituelle, La Revue des Jeunes, l'Aube, Esprit, s'inspiraient constamment de lui ». Maritain, ajoute$\mathrm{t}$-il, est attaqué de toutes parts, comme le fut le Christ.

*FOURNIER, R. La Tbéologie de l'Action catholique, Montréal, Grand Séminaire/Granger Frères (coll. «Theologica Montis Regii »), 1940. [Cloutier 1997, 406]

«Humanisme intégral figure parmi les ouvrages recommandés aux futurs prêtres du diocèse de Montréal », notait Y. Cloutier [1997, 406-407]. En effet, ce livre de Maritain figure dans la bibliographie donnée en début de volume. Dans son explication des doctrines théologiques qui sous-tendent l'action catholique, R. Fournier fait référence à plusieurs ouvrages de Maritain pour éclairer des points tels que l'aspect social de la nature humaine et la notion de participation (sont cités Humanisme intégral, Trois Réformateurs, Du régime temporel et de la liberté, Science et sagesse et Les Degrés du savoir).

*ÉLIE, Robert. «Le sens poétique », La Relève, $1{ }^{\text {ère }}$ série, $\mathrm{n}^{\circ} 8$ (mars 1935), p. 205-207.

R. Élie oppose une poésie moderne abstraite, intellectualisée et sans contact avec le réel, à l'image du monde moderne, à une veine poétique pure, incarnée par C. Baudelaire et $\mathrm{P}$. Claudel, qui rattache le réel aux réalités supérieures spirituelles. Ce texte est structuré par la théorie des âges développée par Maritain dans Humanisme intégral. 
*__. «L'art dans la cité », La Relève, $2^{e}$ série, no 3 (novembre 1935), p. 84-88.

R. Élie s'appuie sur Art et scolastique et la Réponse à Jean Coctean pour développer une réflexion sur l'art.

*__. «Rupture », La Relève, $2^{\mathrm{c}}$ série, $\mathrm{n}^{\circ} 6$ (février 1936), p. $172-177$.

L'influence du philosophe se fait sentir dans cette critique du dualisme et de la séparation de l'homme moderne, ainsi que dans quelques remarques sur le communisme. On trouve une longue citation de $D u$ Régime temporel et de la liberté.

*__. "Le Christ et l'ouvrier », La Relève, $3^{\mathrm{e}}$ série, n ${ }^{\text {os }}$ 5-6 (avril-mai 1937), p. 158-160.

Compte rendu d'un numéro de l'hebdomadaire $S_{e p t}$ consacré à l'ouvrier (4 année, $\mathrm{n}^{\circ} 155$ (12 février) : ce numéro contient un article de Maritain intitulé « Avec le peuple » $[S C J M 10$, p. 22]). L'article de R. Élie contient une longue citation de Maritain soutenant qu'il faut, à l'exemple du Christ qui a vécu parmi eux et a souffert avec eux, exister avec les ouvriers. R. Élie reprend aussi les propos de Maritain qui explique la nécessité de rejoindre les masses ouvrières et les raisons éthiques pour tenter de le faire : elles sont une réserve de nonpharisaisme ; elles importent par le nombre, car « c'est dans la masse que la vie jette ses racines "; et enfin, du point de vue historique, la masse ouvrière accède maintenant à sa majorité.

ESCHMANN, I. Th. "In Defense of Jacques Maritain", The Modern Schoolman [St. Louis], vol. XXII (May 1945), p. 138-208. [Houde 1973-II, 216]

Défense de Maritain contre C. De Koninck. 
FRA DOMENICO. «Chronique. Le Thomisme chez les laïcs », La Revue dominicaine, vol. XXVII, ${ }^{\circ} 3$ (mars 1921), p. 85-87. [Cloutier 1995]

Une partie de la "Chronique » de Fra Domenico présente les informations suivantes. Les formations lycéenne et universitaire françaises, laïques, tendaient à séparer l'élite du thomisme. Mais les thèses thomistes sont maintenant admises comme matières à l'examen en Sorbonne (85). C'est donc la promesse d'un avenir pour la philosophie de l'Église (86). L'auteur souligne les honneurs faits au thomisme dans la Revue universelle, " organe du parti de l'Intelligence ». Maritain est considéré ici comme « le philosophe laïque du jour »; bien qu'il ne soit "pas disciple de Rome », l'auteur cite C. Maurras qui encense Maritain (86). D'autres mouvements thomistes sont enfin désignés, dont la nouvelle faculté de philosophie de l'Université de Montréal (86-87).

GAGNON, Jean-Louis. "Un maitte, pas un fossile », Vivre, vol. I, n ${ }^{\circ} 5$ (décembre 1934), p. 25-28.

Ce texte fait suite à «Des maitres, pas des fossiles", article du même auteur, paru dans le vol. $1, \mathrm{n}^{\circ} 3$, p. 5 7. Cet article établissait un contraste entre le renouveau de la jeunesse française de l'après-guerre et la jeunesse canadienne-française, relevant notamment l'inanité de l'instruction au Canada. L'élève y désapprend à penser, manque d'audace, a peur. La jeunesse "veut [...] des chefs [pas des fossiles] qui sauront canaliser ses énergies tout en lui gardant son personnalisme » (7). Le présent article est un compte-rendu commenté d'une causerie donnée à l'Université Laval à l'intention des professeurs de philosophie, laquelle "donne raison» aux propos tenus par J.-L. Gagnon dans le numéro précédent. 
- " De Maritain à l'abbé X, en passant par un laïque ", Vivre, vol. I, no 6 (janvier 1935), p. 18-19.

Réplique de Gagnon à la suite d'une réponse à son article «Un maitre, pas un fossile » publiée dans la tribune du lecteur de l'Ordre du 12 décembre 1934 ( $\mathrm{Vi}$ vre reproduit la lettre). L'échange s'inscrit dans le cadre de la visite de Maritain à Québec. Discussion sur l'enseignement (laïc et religieux) au Québec.

GAUVREAU, Michael. The Catbolic Origins of Quebec's Quiet Revolution, 1931-1970, Montréal, McGill-Queen's University Press, 2005.

Cet ouvrage défend la thèse voulant que les idéaux de la Révolution tranquille ont été forgés en grande partie à l'intérieur des milieux et institutions catholiques, en particulier au sein des mouvements d'Action catholique spécialisée. M. Gauvreau insiste sur l'identification, dans le discours des promoteurs de l'Action catholique, de l'Église aux valeurs de la jeunesse, une idée empruntée aux mouvements "non-conformistes" français des années 1930 ; à ce titre, l'humanisme intégral de Maritain fait partie, selon M. Gauvreau, des sources d'inspiration des mouvements d'Action catholique. Nombreuses références à Maritain.

GILMARD [pseudonyme de Gérard Petit]. «Jacques Maritain », La Relève, 3 série, n० 8 (1937), p. 200-208.

Survol de la vie et de la pensée de Maritain (Antimoderne, Trois Réformateurs, Réflexions sur l'intelligence, Les Degrés du savoir). Le même texte sera repris dans La Vraie France (voir notice suivante) [Houde 1973-II, 215].

GILMAR [pseudonyme de Gérard Petit]. La V raie France, Montréal, Fides, 1941.

Série d'essais sur les écrivains français catholiques de l'entre-deux-guerres : Ernest Psichari, Charles Péguy, 
Léon Bloy, Paul Claudel, François Mauriac, Jacques Maritain (p. 102-116), Philippe Pétain, Jacques Copeau, Henri Ghéon, Dom Bellot. Le pseudonyme de l'auteur serait la contraction de Gilson et Maritain [Houde 1973II, 215].

HAUSER, Claude. "Introduction " à D'un monde à l'autre... Joumal d'[Auguste Viatte,] un intellectuel jurassien au Québec (1939-1949), vol. I mars 1939 - novembre 1942, Québec/ Paris/Courrendlin, PUL/L'Harmattan/Éditions Communication jurassienne et européenne, 2001, p. xi-xlviii.

Auguste Viatte, d'origine suisse et naturalisé français, est professeur de littérature française à l'Université Laval de 1933 à 1949. Cette introduction à la publication de son journal offre un tour d'horizon critique des relations, directes et indirectes, entre lui et Maritain. Celles-ci restent en général assez distantes. Les deux hommes sont appelés à collaborer, notamment, au moment de la rédaction du manifeste Devant la crise mondiale : manifeste de catboliques européens séjournant en Amérique (1942), rédigé à l'initiative d'A. Viatte et du Père Delos. Le texte du journal présente quelques passages sur Maritain.

HÉBERT, Pierre et Élise SALAÜN. Censure et littérature au Québec. Des vieux couvents au plaisir de vivre 1920-1959, Montréal, Fides, 2004.

P. Hébert voit l'humanisme intégral comme « une philosophie de récupération censoriale », une manière pour les censeurs d'intérioriser la censure. "L'humanisme intégral récupère les velléités d'émancipation personnelle en les intégrant dans une perspective globale, chrétienne. Toutes les activités de la personne, toutes les entreprises sociales doivent être comme innervées par la divinité. » (128) Il ne nomme pas Maritain ici, mais y fera référence plus loin dans la même optique (221). Il 
faut néanmoins tenir compte du fait que l'humanisme intégral dépasse la seule personne de Maritain. P. Hébert traitera cette hypothèse qui touche à la réception québécoise de Maritain à propos de la revue Lectures de Fides (chap. 4).

*HERTEL, François. " Position du personnalisme », L'Action nationale, vol. XI, $\mathrm{n}^{\circ} 2$ (février 1938), p. 95-116.

Hertel s'appuie sur la définition de la civilisation donnée par Maritain dans Humanisme intégral, pour cet essai où il définit les notions de personne et d'individu, avant d'énoncer ce que seraient les grandes lignes d'une civilisation personnaliste.

«Hommage à Maritain », La Rotonde, jeudi 25 avril 1940. [Sylvestre 1983]

Double page consacrée à Jacques et Raïssa Maritain dans le journal des étudiants de l'Université d'Ottawa. Guy Sylvestre est alors directeur de La Rotonde. Contient les textes suivants: Swann [pseudonyme de G. Sylvestre], "Le drame de Jacques et Raïssa Maritain »; Raïssa Maritain, "La Croix du sud» (poème tiré de Lettre de nuit) ; Adéodat Zoppin, "Maritain et l'Art "; Henri Charbonneau, « Maritain et la Cité chrétienne »; Guy Sylvestre, « La sagesse de Maritain ».

"Hommage à Jacques Maritain ", La Nowvelle Relève, vol. II, $\mathrm{n}^{\circ} 2$ (décembre 1942), p. 65-98 et 117.

Numéro spécial à l'occasion du soixantième anniversaire de Jacques Maritain. Voir les notices de chacun des articles dans cette section. 
HOUDE, Roland. « Mort du philosophe, vie de la philosophie - Jacques et Raïssa Maritain au Québec », Relations, $n^{\circ} 383$ (juin 1973), p. 166-168.

À l'occasion de la mort de Jacques Maritain, R. Houde livre ses souvenirs du philosophe et de son influence au Québec. Repris dans Notes et documents, $\mathrm{n}^{\circ} 13$ (octobre-décembre 1978), p. 16-19.

-. "Jacques et Raissa Maritain au Québec, II — éléments de bibliographie critique ", Relations, $\mathrm{n}^{\circ} 384$ (juilletaoût 1973), p. 214-217.

Repris sous le titre « Répertoire bibliographique Maritain au Québec ", dans Notes et documents, $\mathrm{n}^{\circ} 26$ (janvier-mars 1982), p. 32-42.

*HURTUBISE, Claude. «De la Révolution spirituelle, préliminaires ", La Relève, $2^{e}$ série, $\mathrm{n}^{\circ} 3$ (novembre 1935), p. 78-83. [Houde 1973-II, 215]

Le propos de C. Hurtubise repose sur le présupposé de la " nécessité d'une révolution où l'esprit soit le principe informant" (78). L'auteur tente de définir cette révolution spirituelle qui s'accomplit dans la longue durée et dont le «but » (80), l'« idéal » (81), reste indéterminé (comme demeure volontairement indéterminé le moment de sa réalisation). Cette définition de la révolution se développe avec l'aide de citations et références à Mounier et à Maritain, ainsi qu'au manifeste Pour le bien communt ${ }^{29}$. L'auteur aborde enfin l'exemple de la guerre d'Éthiopie en se référant notamment au manifeste Pour la justice et la pai ${ }^{30}$ et à la tevue $S_{e p t}$ (8283). 
GIRARD, René. «L'œuvre de Maritain. Pour la présenter au public », Le Devoir, samedi 20 octobre 1934, p. 1-2. [Houde 1973-II, 215]

Article sur la pensée de Jacques Maritain en général. Distinction dans l'œuvte de Maritain entre les ouvrages polémiques (contre les erreurs philosophiques modernes) et les ouvrages constructifs (cherchant à réconcilier le monde moderne avec la pbilosapbia perennis). Dessein apostolique de son œuvre. Présentation de plusieurs livres de Maritain et suggestions de lecture. $A r t$ et scolastique est qualifié de chef-d'œuvre. Trois Réformateurs révèle, selon l'auteur, un "grand historien ». R. Girard conclut en affirmant que l'œuvre de Maritain «mérite d'être lue ».

ISWOLSKY, Hélène. «La maison de Meudon », dans $A u$ temps de la lumière, Montréal, Éditions de L'Arbre, 1945, p. 83-100. [Houde 1973-I, 168]

Souvenirs des soirées de tenues par les Maritain dans leur maison de Meudon.

JAMET, Dom Albert, O.S.B. «M. Maritain. Un penseur? Oui. Mais un chef ?", Le Devoir, samedi 15 mai 1943, p. 1 2. [Houde 1973-II, 216]

Début d'une controverse qui opposera le religieux au philosophe. L'auteur attaque Maritain à la suite de la diffusion d'une causerie, les 2 et 9 mai 1943, sur les ondes de Radio-Canada. Dom Jamet lui reproche son philosémitisme, son retard à condamner L'Action franfaise avant sa mise à l'Index, ses positions durant le conflit espagnol et son opposition à Vichy. Il rappelle que l'Eglise de France appuie le gouvernement de Vichy et que Rome l'a reconnu. L'auteur appuie à plusieurs teprises sur la question juive, qui obsèderait et aveuglerait Maritain; de même il cherche à le discréditer à cause de sa condition de converti. Son objectif est de 
détruire le capital symbolique de Maritain. Il affirme que s'il n'était de la guerre, celui-ci ne serait pas reconnu en France, ni écouté de personne. Son succès en Amérique et ses prises de positions politiques irritent Dom Jamet : il veut bien reconnaitre ses qualités dans le domaine de la spéculation philosophique, mais refuse de le considérer comme un chef. Le rôle de $\mathrm{Ma}$ ritain comme médiateur après la condamnation de L'Action française est perçu ici négativement, comme un signe d'aveuglement.

—. "Dom Jamet répond à M. M. Raymond », Le Canada, 31 mai 1943.

Réponse à l'article de Marcel Raymond du 21 mai (voir notice ci-dessous).

LAFLEUR, Bruno. "Promenade sur la terrasse avec Jacques Maritain ", L'Événement, mardi 9 octobre 1934, p. 3.

Entrevue avec Maritain : il est question de Péguy et Psichari et des relations qu'il a entretenues avec eux ; Maritain commente et corrige les propos des frères Tharaud sur le sujet.

-. « M. Jacques Maritain », L'Hebdo Laval, 12 octobre 1934, p.1-2 $2^{31}$.

Hommage à Maritain et reconnaissance de son enseignement et de son influence. « M. Jacques Maritain n'est pas un philosophe - ou plutôt c'est un philosophe véritable [...]. Son enseignement s'adresse à des esprits, et à des esprits supérieurs, mais aussi et peut-être davantage à des cœurs. Ne lui faisons pas l'injure de l'admirer en dilettantes. 》

LAMONDE, Yvan. Histoire sociale des idées au Québec. $1896-$ 1929, Montréal, Fides, 2004.

Le chapitre VIII porte sur L'Action française de Montréal et de Paris. 
*LAURENDEAU, André. Notre nationalisme, Montréal, Tracts Jeune-Canada, n' 5 (1935).

La première partie de cet essai est structurée selon la distinction maritainienne entre l'agir en tant que cbrétien et l'agir en cbrétien. L'auteur cite, pour référence, un article de Maritain paru dans Sept. La seconde partie développe la forme de nationalisme adoptée par A. Laurendeau et s'éloigne de Maritain.

-. "On juge la "Relève" », Le Devoir, samedi 24 octobre 1936 , p. 2.

Le sous-titre précise: "Témoignage du P. Paul Doncour et de MM. Jacques Maritain, Emmanuel Mounier, Daniel-Rops et Emile Baas ". L'article est repris dans L'Action catholique du 4 novembre 1936, p. 4 [SCJM 10, p. 19].

-. "Un "hommage à Jacques Maritain" ", L'Action nationale, vol. XX, n 4, (décembre 1942), p. 319-323.

Écrit à l'occasion de la parution du numéro hommage de La Nowvelle Relève. Laurendeau rappelle la dette passée envers Maritain et lui rend hommage malgré les divergences présentes (à propos de la guerre). L'auteur termine en affirmant la nécessité d'une indépendance d'esprit et de conscience par rapport au maître, et dans l'absolu.

*LAURENDEAU, Arthur. «Le catholicisme et l'art ", L'Action franfaise, vol. X (juillet 1923), p. 5-15.

Étude sur les relations entre le beau et le vrai, à travers une critique de l'esthétique classique et un plaidoyer pour une esthétique catholique délivrée de la morale. Plusieurs références à Art et scolastique (Paris, Librairie de l'Art Catholique, 1920). 
- "Sur deux livres de Maritain », L'Action nationale, vol. XVII, n 3 (mars 1941), p. 236-242.

Réflexion à partir de Crépuscule de la civilisation (1939) et A travers le désastre (1940). L'auteur émet des réserves sur le dernier volume à cause de la sévérité de Maritain envers le maréchal Pétain.

LE CAVALIER, Louis. "Un apôtre laï : Jacques Maritain ", Le Semeur, vol. XXV, no 1 (août 1928), p. 6-8.

Article extrêmement élogieux à l'égard de Maritain : considéré comme «à coup sûr le plus ardent et le plus clairvoyant » parmi les artisans de la «magnifique floraison catholique » de France. L'auteur rappelle sa conversion puis sa découverte de saint Thomas, mentionne quelques controverses (avec le Père L. De Grandmaison), cite un passage de la Réponse à Jean Cocteau et mentionne élogieusement Antimoderne et Primauté du spirituel. Il admire les qualités de mystique de Maritain et le considère comme «l'un des modèles les plus parfaits de l'apôtre laïc. "

E. L. [Eugène L'Heureux]. «Petites notes: Christianisme et monde chrétien ", L'Action catholique, lundi 15 octobre 1934, p. 4.

Réflexion sur le manque de christianisme de plusieurs chrétiens, suscitée par les conférences de Maritain.

LE MOYNE, Jean. «Illuminations et sécheresses», La Relève, $4^{e}$ série, $\mathrm{n}^{\circ} 4$ (avril 1938), p. 111-117.

Recension du numéro d'octobre 1937 des Études carmélitaines ( $22^{e}$ année, vol. II) sur la psychologie religieuse et contenant un article de Raïsa Maritain intitulé «Du recueillement poétique ». 
—. "La pensée de Saint Paul », La Nouvelle Relève, vol. I, $\mathrm{n}^{\circ} 3$ (décembre 1941), p. 164-175.

Étude sur le livre du même nom paru à New York (Maison française, 1941), un choix de textes de saint Paul présentés et commentés par Maritain. J. Le Moyne y décrit un Maritain non seulement philosophe, mais théologien et mystique (165), qui offre sur saint Paul «une initiation très simple et très accessible », et non une biographie ou un commentaire exégétique (169). Il souligne la pertinence du chapitre intitulé «le mystère d'Isräl », « où [Maritain] réunit une série de textes [...] d'une importance extrême en raison des ravages croissants que fait chez nous l'antisémitisme » (171-172).

—. «Dom Jamet à côté de M. Maritain », La Nouvelle Relève, vol. II, $\mathrm{n}^{\circ} 7$ (juin 1943), p. 385-390.

Réponse à Dom Jamet (Le Devoir, 15 mai 1943). La défense de Maritain s'appuie sur son influence auprès des catholiques de France et du monde entier. À propos de l'affaire de L'Action française, Le Moyne écrit: " est-ce donc si extraordinaire que la lumière lui soit venue de Rome ? Est-ce donc si honteux que d'avoir obéi au chef de l'Église et obéi jusqu'au plus intime de son être, jusqu'à modifier intégralement et sans retour ses opinions et jusqu'à abolir tout regret? Si tel est le cas [...] c'est tout à son honneur [...]» (387). Le Moyne termine sur une peinture de «l'homme de droite» (389).

_. "Les Maritain - de loin, de près », Écrits du Canada francais, $\mathrm{n}^{\circ} 49$ (1983), p. 47-71.

Témoignage sur les relations de l'auteur et du groupe de La Relève avec les Maritain, relations intellectuelles, éditoriales et amicales dont l'auteur évoque les accords et les désaccords. J. Le Moyne affirme avoir pris ses distances avec la philosophie de Maritain. Texte daté 
de septembre 1983. Repris dans Roger Rolland et Gilles Marcotte (dir.). Jean Le Moyne. Une parole vébémente, Montréal, Fides, 1998.

LONGPRÉ, Anselme. La pensée catholique, Montréal, Éditions du Devoir, 1936. [Cloutier 1997]

«Essai bibliographique d'études religieuses [composé d'Jun choix succinct de quelques-uns des livres les plus propres à faciliter l'étude de la pensée catholique, condition indispensable de l'Action catholique et de tout effort de restauration sociale $"(7)$. Huit ouvrages de Maritain sont répertoriés et commentés (notices dans la section 3.2).

MAURER, Armand. «Some memories of Jacques Maritain », "Maritain and Gilson in Canada [dossier] ", Maritain Studies/Études maritainiennes, vol. 15 (1999), p. 11-12.

Premier texte d'un dossier comprenant trois articles sur Maritain au Canada et portant principalement sur sa présence à Toronto.

MEUNIER, E.-Martin et Jean-Philippe WARREN. Sortir de la "Grande noirceur". L'borizon personnaliste de la Révolution tranquille, Sillery, Septentrion, 2002.

Ce petit ouvrage défend la thèse voulant que la Révolution tranquille aurait obéi à une inspiration profondément religieuse, à travers un certain nombre d'intellectuels influencés par le catholicisme "non-conformiste " des mouvements Ordre nouveau et Esprit. Si l'influence de Maritain au Québec est très peu étudiée ici (l'accent est mis sur l'influence d'E. Mounier et d'Esprit dans l'après-guerre), les auteurs reconnaissent, dans la première partie du livre, son rôle dans le développement d'une « éthique personnaliste » à l'intérieur de la pensée catholique, opposée à l'« éthique post-tridentine » traditionnelle. 
MICHEL, Florian. "Jacques Maritain en Amérique du Nord - I : 1933-1940", Cahiers Jacques Maritain, no 45 (décembre 2002), p. 27-86.

—. «Un réseau d'intellectuels européens en Amérique du Nord. Diffusion, réception et américanisation de la pensée catholique. Années 1920 - années 1960 », doctorat en Histoire, Paris, École pratique des Hautes Études, 2006.

MICHON, Jacques. «Les Éditions de l'Arbre », Voix et Images, 41 (hiver 1989), p. 194-210.

Histoire et analyse de la maison d'édition fondée en 1941 par R. Charbonneau et C. Hurtubise de La Relève. Maritain est considéré comme un parrain des Éditions de l'Arbre. Crépuscule de la civilisation est leur première parution en 1941 et remportera un bon succès (197). Maritain a une influence certaine sur les orientations de la maison d'édition, dirige officieusement une collection ( Problèmes actuels »), en plus de mettre les éditeurs en contact avec plusieurs auteurs (198-199). On se rappelle que Y. Cloutier parlait de " tutelle éditoriale i [Cloutier 2002]. Selon J. Michon, « La diminution de cette influence se fait sentir après $1945 »$ (199).

__. «Les Éditions de l'Arbre 1941-1948 », dans Jacques Michon (dir.), Éditeurs transatlantiques, Sherbrooke/Montréal, Ex libris/Tryptique, 1991, p. 13-41.

"M. Jacques Maritain rencontre les jeunes », La Patrie, vol. 56, no 199 (17 octobre 1934), p. 9.

Très court article faisant état d'une rencontre de Maritain avec les jeunes de La Relève et des Jeune-Canada, la veille.

MOUGEL, René. "Les années de New York, 1940-1945 ", Cabiers Jacques Maritain, $\mathrm{n}^{\text {os }}$ 16-17 (avril 1988), p. 7-28. 
O'CONNOR, John J. «Fraternal Twins: The Impact of Jacques Maritain on Callaghan and Charbonneau », Mosaic: A Journal for the Interdisciplinary Study of Literature, 14, 2 (1981), p. 145-163.

L'auteur étudie l'influence de Maritain sur les romans Ils posséderont la terre de Robert Charbonneau (1941) et They Shall Inberit the Earth de l'écrivain canadien Morley Callaghan.

\section{PARTIKIAN, Pierre et Louis ROUSSEAU. La Théologie} québécoise contemporaine (1940-1973): genèse de ses producteurs et transformations de son discours, Québec, Institut supérieur des sciences humaines, Université Laval, 1977.

Étude surtout quantitative basée en grande partie sur un questionnaire distribué à environ 1000 théologiens québécois. En ce qui concerne leurs influences intellectuelles, les répondants ont dû̀ nommer les trois auteurs les ayant le plus influencés à trois moments de leur carrière (études de $1^{\text {er }}$ cycle, études avancées et carrière d'enseignant). " [N]ous avons pu constater un groupe de plus de trois cent producteurs d'influence [dans lequel] dominaient un certain nombre de ténors [...]», dont Maritain fait partie (103, en note). Les auteurs choisissent d'étudier ces influences selon la nationalité des auteurs (influence française, italienne, allemande, etc.) (104). Thomas d'Aquin est l'influence dominante de tous les théologiens interrogés ; elle n'a jamais cessé de croitre de 1920 à 1952 (122). L'influence française est surtout celle de « l'école dominicaine française du $\mathrm{XX}^{e}$ siècle » (127) : y figurent le P. Garrigou-Lagrange (127129), Maritain (129-130), M.-D. Chenu et Y. Congar. Maritain représente le "catholicisme [...] comme une alternative valable à la pensée contemporaine » (129). "Il est assez remarquable de constater que Maritain a exercé le plus clair de son influence au Québec dans les années trente, et cela au niveau des premières Études 
théologiques. Faut-il y voir le reflet de l'importance des questions logiques et épistémologiques à cette étape de la formation? Sans doute. À ce titre on peut donc dire que c'est le néo-scolastique plutót que le penseur politique qui aura touché les théologiens québécois » (130).

POMEYROLS, Catherine. «Les échos de la condamnation de L'Action française au Québec ", Sources. Travaux bistoriques, 53-54 (2000), p. 61-72.

C. Pomeyrols analyse les réactions québécoises à la condamnation par Rome de L'Action française de Paris à travers le traitement de l'événement dans divers journaux de la province : Le Devoir, L'Action catholique, Le Courrier de Saint-Hyacintbe, Le Progrès du Saguenay, Le Semeur, La Revue dominicaine. Selon l'auteur, le reniement de L'Attion française ne fut pas chose facile. Elle interprète le silence de certains journaux sur l'affaire après la condamnation dans le sens d'un désaccord avec Rome.

RAYMOND, Marcel. "La jeunesse de Jacques Maritain », La Nouvelle Relève, vol. II, $\mathrm{n}^{\circ} 2$ (décembre 1942), p. $90-98$ et 117.

Sur les relations de Maritain avec E. Psichari, C. Péguy, H. Bergson et L. Bloy, dans un numéro hommage à Maritain.

-. "Jacques Maritain, le Roseau d'Or et la Nouvelle Revue françise », Le Canada, 21 mai 1943, p. 4. [Cloutier 2002, 231]

Réponse à Dom Jamet. L'auteur perçoit chez Dom Jamet une crainte " de se sentir dépossédé par un laïc des textes évangéliques, apostoliques [...]». Il critique les moyens mensongers utilisés par Dom Jamet (un clerc) : ce dernier associe Maritain à la NRF pour laisser entendre qu'il a des sympathies communistes, et le 
blâme d'avoir publié au "Roseau d'Or " un livre qui n'y a jamais paru! Pour M. Raymond, le courage de Maritain fait contraste avec ces attaques malhonnêtes. Il voit dans l'article de Dom Jamet un exemple du désaveu de l'action catholique des laïcs prônée par le Pape Pie XI. Il ne répond pas aux accusations de Jamet en ce qui a trait à l'affaire de L'Action francaise.

. «Dom Jamet ou l'art d'avoir raison ", Le Canada, 2 juin 1943, p. 4. [Cloutier 2002, 231]

Réponse à une lettre aux lecteurs de Dom Jamet, ellemême réponse à l'article du 21 mai de $\mathrm{M}$. Raymond. Pas de mention de l'affaire de L'Action française.

[La rédaction]. «M. Maritain, la France et nous », Les Carnets viatoriens, $\mathrm{X}^{\mathrm{e}}$ année, $\mathrm{n}^{\circ} 3$ (juillet 1945), p. 161-167. [Houde 1973-II, 216]

Article polémique. Maritain a critiqué les rédacteurs de la revue, partisans de Pétain, dans un article publié à Paris sous le titre : "La France vue d'Amérique ». Un hebdomadaire montréalais (pas nommé) a secondé Maritain dans ses critiques. Voici la réponse. L'auteur semble vouloir polariser la querelle pour opposer clercs et laics, car Maritain est taxé d'anticléricalisme. On trouve une longue critique de la France anticléricale de la Troisième République, qui a ébranlé, selon l'auteur, la foi en la France du Canadien moyen (162-164). Il est reproché à Maritain de "collaborer» avec des penseurs athées (164-65). L'auteur s'élève contre le libéralisme, qui est « le fanatisme des faibles ", et reproche à Maritain de souhaiter « une France chrétienne et libérale » (166). La France, conclut-il, faillit à sa mission, à son élection chrétienne (166-67). 
RÉGIS, L.-M., O.P. «Un livre. La Philosophie de la nature. Quelques “apories" ", Études et Recherches (Ottawa), Cahier 1 (1936), p. 127-156. [Houde 1973-II, 215]

«La première et peut-être la seule étude canadienne en profondeur d'un ouvrage de Maritain ", selon R. Houde. L'auteur prend un livre de Maritain, La Pbilosopbie de la nature: essai critique sur ses frontières et son objet (Paris, Téqui, 1935), pour prétexte à ses réflexions sur les relations entre Philosophie et Sciences. Il entreprend une critique serrée du livre, portant dans un premier temps sur la notion d'abstraction, puis dans un second temps sur la distinction entre la philosophie de la nature et la métaphysique. L'étude est appuyée sur une lecture des textes d'Aristote et de saint Thomas, dont l'auteur tire des conclusions qu'il confronte avec celles de Maritain, généralement pour les réfuter. En résumé, l'auteur reproche à Maritain de s'éloigner de la position thomiste. La critique, ici, n'est nullement présentée sur le ton d'une attaque, mais bien comme une discussion toute philosophique : l'auteur remercie Maritain d'avoir éveillé ses réflexions.

*LA RELÈvE. "Pour une démocratie vraie ", La Relève, $4^{\text {e }}$ série, $n^{\circ} 9$ (juillet 1939), p. 265-267.

Prise de position contre la guerre et pour un « renouvellement des formes actuelles de la démocratie », afin de parvenir à une « démocratie véritable qui sauvegarderait les droits de la personne en l'intégtant dans une communauté humaine, en établissant une tension féconde entre le bien de l'individu et le bien commun. » On trouve plusieurs références et citations de Maritain. 
ROY, Christian. «De La Relève à Cité Libre : avatars du personnalisme au Québec », Vice versa, décembre 1986janvier 1987, p. 14-16.

Survol de l'influence personnaliste au Québec, de La Relève à Parti Pris en passant par Cité Libre. L'auteur soutient la thèse selon laquelle le personnalisme aura permis à la notion d'individu de "s'acclimater " au Québec, en quelque sorte malgré elle, puisque le personnalisme se méfie de la notion d'individu, à laquelle il substitue celle de personne.

ROY, Maurice, prêtre. "Jacques Maritain ", L'Action catholique, vendredi 12 octobre 1934, p. 4.

Publié dans la colonne principale de la page éditoriale. Comparé à E. Psichari et à C. Péguy, avec qui il symbolise pour les Canadiens le renouveau catholique français, Maritain est considéré par l'auteur comme le plus illustre de ce mouvement. M. Roy se réjouit que la connaissance de l'homme (par ses conférences) s'ajoute à celle des livres : il voit en lui un modèle pour le Canada français, qui doit allier à «l'effervescence de la jeunesse » les « fortes disciplines de la pensée ».

Le Scrutateur. "Pétain ou Maritain?", Les Camets viatoriens, $\mathrm{VI}^{\mathrm{e}}$ année, $\mathrm{n}^{\circ} 2$ (avril 1941), p. 129-130. [Houde 1973-II, 216]

Critique de l'article paru dans La Revue dominicaine en janvier 1941 : «Le peuple de France ».

SIMARD, Émile. "Jacques Maritain », L'Action catbolique, samedi 20 octobre 1934, p. 17.

Cet article est publié dans la page « La voix de la jeunesse catholique » et l'auteur est membre du comité régional de l'ACJC. À la suite des conférences de Maritain à Québec, le philosophe est décrit comme un " apôtre » qui a laissé dans l'âme des jeunes plus qu'un 
souvenir : un idéal. Le jeune homme a bien assimilé la leçon de Maritain et reprend ses idées : sanctification de la vie profane, chrétienté analogue au monde médiéval, etc. É. Simard trouve dans l'enseignement de Maritain un appel à l'apostolat des Canadiens français en Amérique du Nord.

SIMON, Yves R. "Pour le soixantième anniversaire de Jacques Maritain", La Nouvelle Relève, vol. II, $\mathrm{n}^{\circ} 2$ (décembre 1942), p. 66-69.

Dans un numéro spécial consacré à Maritain. Ancien élève de Maritain du temps de son enseignement à Paris durant les années 1920, Y. Simon rappelle les soirées de Meudon, où l'on étudiait la philosophie de saint Thomas en restant « aussi loin que possible de toute version rationaliste du thomisme » et fait l'éloge des Maritain. Le même texte paraît dans Le Canada du samedi 23 janvier 1943, p. 4.

SWEET, William. "Études maritainiennes en Amérique du Nord ", Cabiers Jacques Maritain, n' 42 (juin 2001), p. 57-63.

Sur les deux associations Maritain aux États-Unis et au Canada.

SYLVESTRE, Guy. "Jacques Maritain apôtre de l'esprit ", Le Droit, samedi 30 août 1941, p. 18. [SCJM 19, p. 35]

Toute la page est consacrée à Jacques et Raïssa Maritain et comprend des extraits de leurs cuvres (voir notices dans les sections 2.1 et 2.2 ).

—. "Une poétesse mystique ", Le Canada français, vol. XXX, no 1 (septembre 1942), p. 30-35. [Sylvestre 1983, 112]

Étude de l'œuvre poétique de Raïssa Maritain. Sa poésie est, pour l'auteur, une preuve que « l'amour mystique n'abolit point l'amour humain, qu'il ne faut pas 
nécessairement haïr le monde pour aimer Dieu ». L'auteur désire manifestement résoudre le conflit opposant corps et esprit dans la pensée catholique.

—. "Raïssa Maritain », Poètes catboliques de la France contemporaine, Montréal, Fides, 1943, p. 95-105. [Houde 1973-II, 216]

Reprise du texte de la notice précédente.

—. "Le don d'écouter chez Maritain », Écrits du Canada français, $\mathrm{n}^{\circ} 49$ (1983), p. 88-90.

Témoignage sur les relations de l'auteur avec les Maritain ; informations sur le programme de l'Institut de philosophie de l'Université d'Ottawa (1937-1941) et sur l'influence qu'y a exercée Maritain.

Un néophyte édifié. «Les parias, les intouchables et Dom Jamet ", Le Canada, samedi 29 mai 1943, p. 4.

L'auteur de cette lettre au directeur du Canada défend Maritain et attaque Dom Jamet avec les armes de l'ironie.

VANDERPELEN-DIAGRE, Cécile. «À l'ombre des clochers. Le monde catholique et la littérature au Québec (1918-1939) ", Revue d'bistoire de l'Amérique française, 58, 1 (été 2004), p. 3-26.

Discussion de l'influence de Maritain sur les membres du mouvement de La Relève en ce qui a trait aux relations entre littérature et morale (p. 20-24). L'horizon de l'article est l'émergence d'une écriture romanesque catholique engagée (sur le modèle du « renouveau catholique " français mené par Bernanos, Mauriac et Daniel-Rops), qui tarde à apparaître au Québec, ce que cherche à expliquer l'auteur. 
VOYER, Raymond M., Dominicain. «Maritain à Montréal ", L'Action nationale, vol. IV, n' 3 (novembre 1934), p. 193-201.

L'auteur analyse l'impression produite par les conférences de Maritain (octobre 1934), en particulier chez les laïcs. Une bonne part des auditeurs (laïcs d'âge mur) n'avait pas fait de philosophie depuis le collège : « D'un beau mouvement d'ensemble, les laïcs s'étaient [jadis] désintéressés d'une culture qui regardait les “curés". Or ils étaient là $[. .$.$] ». Ceux-ci eurent-ils des difficultés à$ suivre le philosophe? Eurent-ils des remords d'avoir «abandonné » la pensée? $(194,197)$ «Ce qu'ils s’étaient habitués à regarder comme de vaines querelles [...] tout cela s'animait soudain, laissait transparaître des influences latentes et impérieuses à travers les angoisses et les espoirs de nos situations sociales bien actuelles et bien concrètes. [...] se dessinait [...] cette idée de la portée pratique, dans la vie d'une société, des abstractions de ses philosophes. " (195) Une autre part de l'auditoire était composée de jeunes (étudiant(e)s et jeunes professeurs), "plus avisés que leurs aînés, énergiquement conseillés par l'inquiétude de leur époque, [...] assez bien préparés à une telle parole " par les cours suivis et la lecture des ouvrages de Maritain (197). L'auteur se félicite du chemin parcouru depuis vingt ans (198). Il exprime, même en tant que prêtre, son admiration pour Maritain et pour sa «façon d'être catholique » (199).

" Alexis Carrel et Jacques Maritain : l'humanisme intégral à la rescousse de la science ", La Revue dominicaine, vol. XLIII, n 2 (septembre 1937), p. 61-70.

L'auteur entreprend une critique de L'Homme, cet inconnu d'A. Carrel. Il approuve ses critiques des sciences exactes et sa volonté de réintégter le spirituel dans l'étude de l'homme, mais regrette qu'il ait entrepris d'étudier la part spirituelle de l'homme précisément à l'aide des 
méthodes expérimentales. Cela fait du livre d'A. Carrel, selon R. Voyer, " une immense glorification de l'esprit scientifique ». L'auteur trace néanmoins des liens entre les «doléances [du $\mathrm{D}^{\mathrm{r}}$ Carrel] contre la fausse notion de la nature de l'homme » et la critique de l'inhumanité du matérialisme moderne développée par Maritain dans Humanisme intégral. Il conseille la lecture parallèle des deux ouvrages: "Je ne sais que [Humanisme intégral pour faire comprendre exactement le livre de Carrel. »

\section{NOTES}

${ }^{1}$ Les résultats de cette enquête menée par Le Nouveau Joumal sont présentés par G. Lesage, o.m.i., dans Notre éveil culturel, Montréal, Rayonnement, 1963, p. $135-170$.

${ }^{2}$ L[ionel] G[roulx], «Primauté du Spirituel, par Jacques Maritain [...] », L'Action française, vol. XVIII, $\mathrm{n}^{\circ} 3$ (septembre 1927), p. 188.

${ }^{3} \mathrm{~N}^{\text {os }} 4-5$, novembre 1982 (pour les années 1930-1934), n 10, octobre 1984 (1935-1938), no 12 , novembre 1985 (1924-1929), n 15 , octobre 1987 (19061923) et no 19, octobre 1989 (1939-1945). Les renvois à ces publications sont indiqués par le sigle SCJM suivi du numéro du supplément et de la page, entre crochets dans le corps du texte.

${ }^{4}$ Nom de famille de l'auteur, date de publication, numéro de page.

${ }^{5}$ Nous remercions Michel Lacroix de l'Université du Québec à Trois-Rivières de nous avoir donné accès à la photocopie de la correspondance MaritainHurtubise conservée à BAC.

${ }^{6}$ Voir le site du Centre : www.maritain.fr.

7 Voir l'article de L. Dewan, «Jacques Maritain and Toronto (A Visit to P.I.M.S.S.M.C. Archives) », Études maritainiennes / Maritain Studies, vol. 15 (1999), p. 13-51.

${ }^{8}$ Ces lettres permettent de croire que le fonds Guy Sylvestre à $\mathrm{BAC}$ est d'une richesse égale à celle du fonds Claude Hurtubise. Le fonds Sylvestre à $\mathrm{BAC}$ ne semble pas encore ouvert (juillet 2007) à la consultation et la notice descriptive 
du fonds est en traitement au moment où nous soumettons notre travail pour publication.

${ }^{9}$ Les éditeurs des (Eutrres completes de Jacques et Raissa Maritain attribuent ce texte, " en bonne part, à la plume de Jacques Maritain » (vol. XV, Fribourg/ Paris, Éditions universitaires/Éditions Saint-Paul, 1995, p. 881). Le journal d'A. Viatte contredit cette version : C. Hauser (dir.), D'un monde à l'autre... Journal d'un intellectuel jurassien an Québec (1939-1949), vol. I, mars 1939 - novembre 1942, Québec /Paris/Courrendlin, PUL /L'Harmattan/Éditions Communication jurassienne et européenne, 2001, p. 295.

${ }^{10}$ Cette revue, éditée par Fides de 1943 à 1946, a été fondée par Guy Sylvestre, par ailleurs chroniqueur littéraire au quotidien $L e$ Droit d'Ottawa. L'expression « Gants du ciel » est tirée de la Lettre a Jacques Maritain de Jean Cocteau (cf. Eunres complètes de Jacques et Raïssa Maritain, vol. III, Fribourg, Éditions universitaires, 1984, p. 669), ce qui indique bien l'importance de la figure de Maritain pour la publication et son fondateur. Sylvestre s'explique à ce sujet dans le texte liminaire du premier numéro.

"Les Carnets viatoriens prennent la suite des Camets du théologue et sont publiés à Joliette.

12 Source: Bibliothèque et Archives nationales du Québec, www2.bnquebec.ca/rfq/auteurs/012182.htm (juillet 2007).

${ }^{13}$ R. Élie, « Pierre Emmanuel », GEutres, Montréal, Hurtubise HMH, 1979, p. 77-78.

14 Source: Bibliothèque et Archives nationales du Québec, www2.bnquebec.ca/rfq/auteurs/012182.htm (juillet 2007).

15 Source: Bibliothèque et Archives nationales du Québec, www2.bnquebec.ca/rfq/auteurs/012182.htm (juillet 2007).

${ }^{16}$ Référence trouvée dans « Euvres de Raïssa Maritain. Bibliographie » dans J. et R. Maritain, Eunres complètes, vol. XV, Fribourg/Paris, Éditions universitaires/Éditions Saint-Paul, 1995, p. 875.

${ }^{17}$ Ibid., p. 875

18 Ibid., p. 876.

${ }^{19}$ Ibid., p. 878.

2) Ibid., p. 879 .

${ }^{21}$ Ibid., p. 879. 
${ }^{22}$ Ibid., p. 879

${ }^{23}$ Ibid., p. 883.

${ }^{24}$ Cité dans ibid., p. 887.

${ }^{25}$ Référence fournie par J. Blais, De l'ordre et de l'aventure, la poésie an Québec de 1934 à 1944, Québec, PUL, 1975, p. 34.

${ }^{26}$ Un certain nombre de comptes rendus d'œuvres de Raïssa Maritain sont signalés par P. Beaulieu et $\mathrm{G}$. Sylvestre dans les témoignages et notes explicatives accompagnant la publication de leurs échanges épistolaires avec les Maritain dans les Écrits du Canada français $\mathrm{n}^{\circ} 49$ (1983). La plupart de ces mentions sont imprécises et nous n'avons pu retracer les articles en question : selon P. Beaulieu, Les Grandes Amitiés et Marc Chagall sont recensés dans Le Canada; G. Sylvestre affirme avoir donné dans Le Droit des articles sur Les Aventures de la grâce et La Conscience morale et l'état de nature.

${ }^{27}$ Référence fournie par J. Michon, Histoire de l'édition littéraire au Québec au $X X{ }^{\prime \prime}$ siècle. Volume 1 : La naissance de l'éditeur (1900-1939), Montréal, Fides, 1999, p. 357.

${ }^{28}$ Nom illisible sur le microfilm du Canada.

${ }_{29}^{9}$ Pour le bien commun. Les responsabilités du Chrétien et le moment présent, Paris, Desclée de Brouwer, 1934. Paru à la suite des émeutes du 6 février 1934 en France, lesquelles ont failli mener à une prise de pouvoir par des mouvements d'extrême-droite. Ce manifeste condamnant autant le fascisme que le communisme porte la signature de Jacques Maritain. Cf. H. Bars, Maritain en notre temps, Paris, Bernard Grasset, 1959, p. 381 ; Bernard Doering, Jacques Maritain and the French Catholic Intellectuals, Notre Dame, University of Notre Dame Press, 1983,p. 70-71.

${ }^{30}$ En réponse au Manifeste des intellectuels francais pour la défense de l'Occident publié en octobre 1935 à l'initiative d'Henri Massis pour empêcher les sanctions contre l'Italie, Maritain signe le Manifeste pour la justice et pour la paix, publié dans Sept et La Vie catbolique, dans lequel sont condamnés l'invasion italienne de l'Éthiopie et le massacre de sa population. Cf. Bars, Maritain en notre temps, p. 382.

${ }^{31} \mathrm{~J}$. Blais répertorie cet article, avec un titre différent, dans De l'ordre et de l'aventure, la poésie au Québec de 1934 à 1944, Québec, PUL, 1975, p. 34. 